Florida International University FIU Digital Commons

\title{
The Field View: An Initial Examination of an Exploratory Eyewitness Identification Procedure
}

Melissa Kavetski

Florida International University, mkavetski@gmail.com

DOI: $10.25148 /$ etd.FIDC000731

Follow this and additional works at: https://digitalcommons.fiu.edu/etd

Part of the Criminology and Criminal Justice Commons, Other Psychology Commons, and the Social Psychology Commons

\section{Recommended Citation}

Kavetski, Melissa, "The Field View: An Initial Examination of an Exploratory Eyewitness Identification Procedure" (2016). FIU Electronic Theses and Dissertations. 2593.

https://digitalcommons.fiu.edu/etd/2593 


\section{FLORIDA INTERNATIONAL UNIVERSITY}

Miami, Florida

\section{THE FIELD VIEW: AN INITIAL EXAMINATION OF AN EXPLORATORY EYEWITNESS IDENTIFICATION PROCEDURE}

A dissertation submitted in partial fulfillment of the requirements for the degree of DOCTOR OF PHILOSOPHY

in

PSYCHOLOGY

by

Melissa Kavetski 
To: Dean Michael R. Heithaus

College of Arts, Sciences and Education

This dissertation, written by Melissa Kavetski, and entitled The Field View: An Initial Examination of an Exploratory Eyewitness Identification Procedure, having been approved in respect to style and intellectual content, is referred to you for judgment.

We have read this dissertation and recommend that it be approved.

Rob T. Guerette

Ronald P. Fisher

Jacqueline Evans

Steve Charman, Major Professor

Date of Defense: July 7, 2016

The dissertation of Melissa Kavetski is approved.

Dean Michael R. Heithaus
College of Arts, Sciences and Education

College of Arts, Sciences and Education

Andrés G. Gil

Vice President for Research and Economic Development and Dean of the University Graduate School

Florida International University, 2016 
(C) Copyright 2016 by Melissa Kavetski

All rights reserved. 


\section{DEDICATION}

I dedicate this dissertation to my parents, Louis and Pam Kavetski. Without your love, patience, and incredible support, I would not have made it this far. 


\section{ACKNOWLEDGMENTS}

First, I would like to thank my major advisor, Steve Charman, for his invaluable guidance and support, not only during this project, but throughout my entire graduate career. I also wish to thank my committee members, Jacki Evans, Ron Fisher, and Rob Guerette for their advice, encouragement, and feedback during this process. It was greatly appreciated.

I would also like to thank Florida International University’s College of Arts, Sciences, and Education and the Department of Psychology. This dissertation was supported, in part, by the College's Data Evidence Acquisition grant and the Department's PSY Graduate Student Seed Fund Award.

I would also like to acknowledge my research assistants, who played a critical role in the completion of this project. Jessica - thank you for your continued support.

I also wish to thank my family - my parents, Michelle, Louis, and David. All of your successes have encouraged me to push through to the end of this process. Your loving support and humor during my many years in graduate school have kept me going. I love you all.

Finally, I would like to thank those who helped me maintain my sanity throughout this tough, but rewarding, process. Ali - I am forever grateful for your friendship and could not have found a better person to lean on while overcoming all the obstacles. My time at FIU was that much better thanks to all our laughs and fun times. And Jordan Your support and patience throughout this journey and your belief in my abilities has meant the world to me. I am very lucky to have you and could not have done this without you. 


\title{
ABSTRACT OF THE DISSERTATION \\ THE FIELD VIEW: AN INITIAL EXAMINATION OF AN EXPLORATORY EYEWITNESS IDENTIFICATION PROCEDURE
}

\author{
by \\ Melissa Kavetski \\ Florida International University, 2016 \\ Miami, Florida

\section{Professor Steve Charman, Major Professor}

The field view is an identification procedure that was recently acknowledged in a national report assessing eyewitness identifications. However, the field view has not been empirically examined to date. In fact, very little is known regarding the effectiveness of the procedure. Because it is an exploratory procedure - used by police when they do not have a suspect in mind - it is important to determine how the field view fares in comparison to the traditional procedures such as lineups and showups, whereby police do have a suspect. Using a controlled, lab-based methodology, Study 1 examined correct and false identifications elicited from the field view procedure and whether filler similarity affects identification accuracy. Results revealed that the exploratory field view can be a harmful procedure, particularly when the perpetrator is not present in the location, as it produced significantly more false identifications (36\%) than both the lineup (13\%) and showup $(5 \%)$ procedures. The reason for this alarmingly high rate of mistaken identifications is that in an exploratory procedure, there is not an a priori suspect, and thus, nobody in the location is known to be innocent, as fillers are in a lineup. Because of this, anyone identified would come under suspicion. A second study further examined 
whether the field view may be an acceptable identification procedure under a different circumstance, namely, when police do have a suspect. Study 2 used a more ecologically valid methodology to examine the hypothesis that this confirmatory field view procedure may fare superior to the showup under the condition that the field view is administered by someone who is blind to the identity of the suspect. Contrary to our predictions, however, all three procedures (i.e., field view with non-blind administration; field view with blind administration; showup) produced comparable correct and false identification rates. Overall, results indicate that a field view may be a viable procedure when it is used as a confirmatory procedure and includes fillers similar to the suspect. More research is needed to determine under what conditions exploratory procedures may be acceptable. 


\section{TABLE OF CONTENTS}

CHAPTER

PAGE

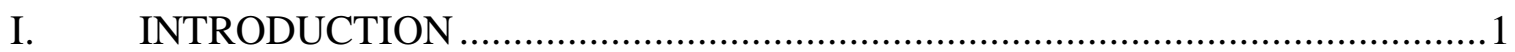

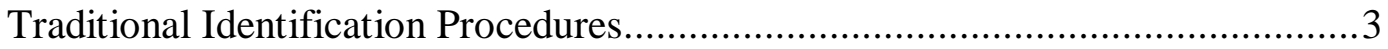

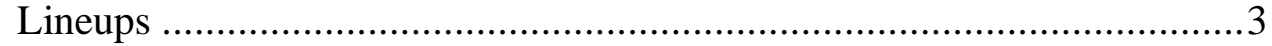

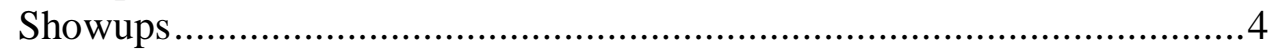

Lineups vs. showups ................................................................. 5

Comparison of the Field View to the Traditional Procedures ............................9

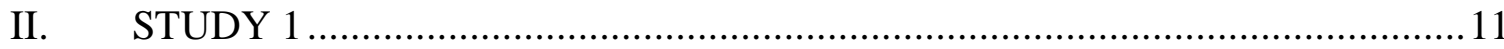

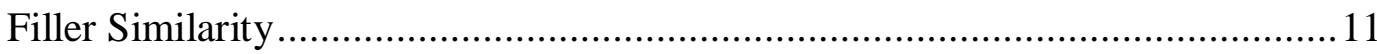

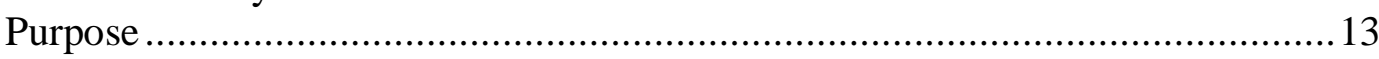

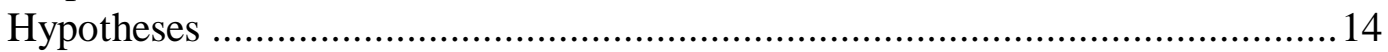

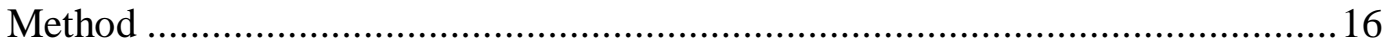

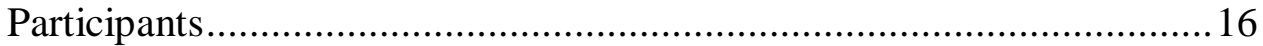

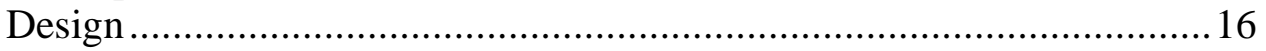

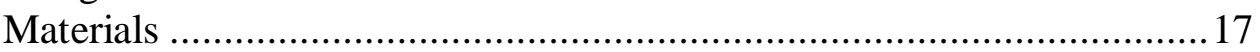

Procedure ............................................................................ 20

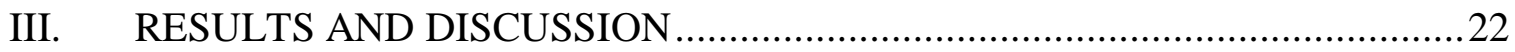

Data Excluded from Analyses ...................................................................22

Comparison of the Exploratory Field View to the Traditional Procedures...........22

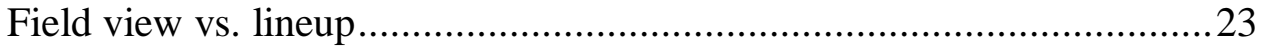

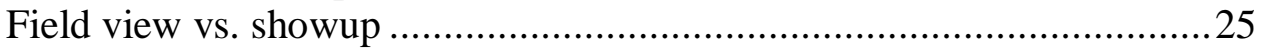

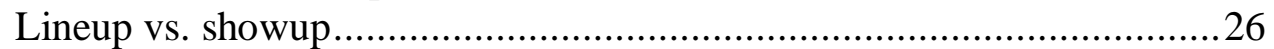

Effect of Filler Similarity .................................................................. 28

Lineup ............................................................................. 28

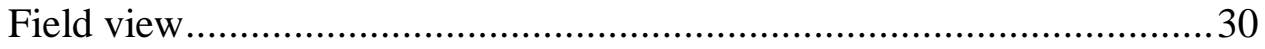

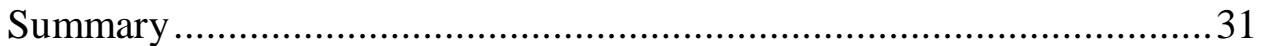

Information Gain Analyses................................................................... 32

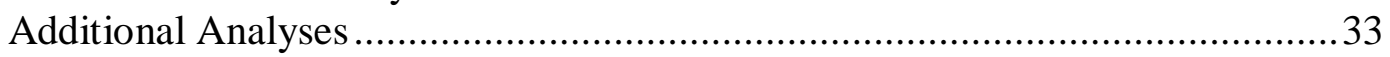

Witnesses' expectations ...................................................... 33

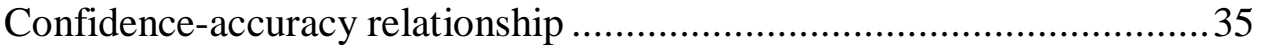

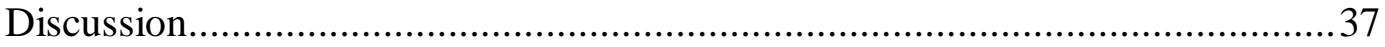

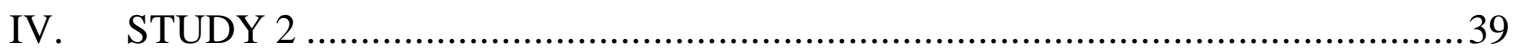

Re-evaluation of Study 1 Data: False Identifications ................................... 40

The Confirmatory Field View Procedure ................................................ 42

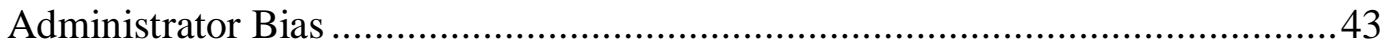

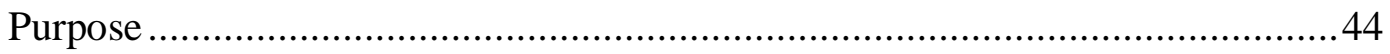

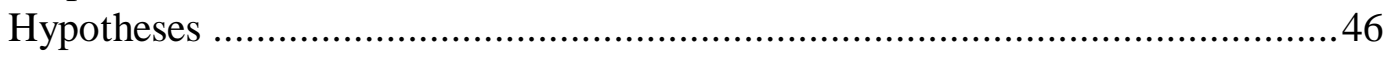

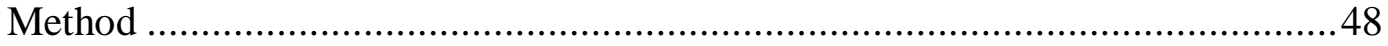

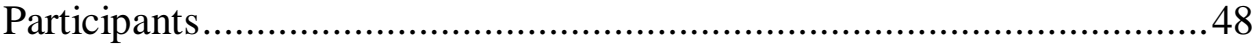




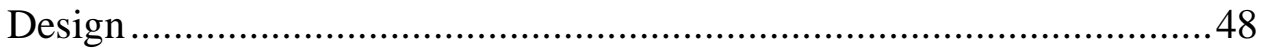

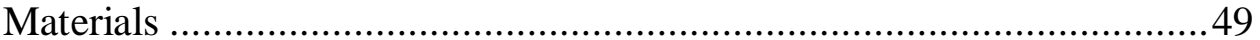

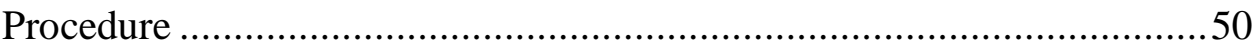

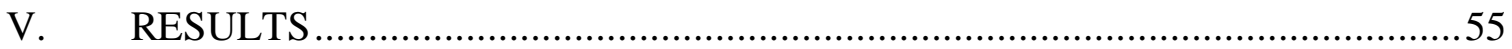

Data Excluded from Analyses ........................................................................55

Comparison of the Confirmatory Field View to the Showup and Effects of

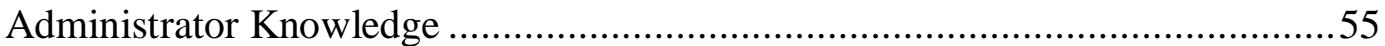

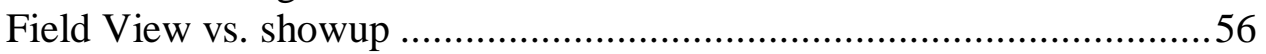

Non-blind field view vs. blind field view .............................................57

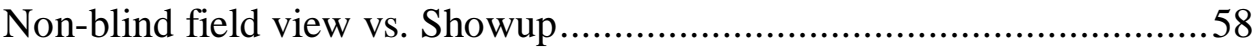

Blind field view vs. showup................................................................60

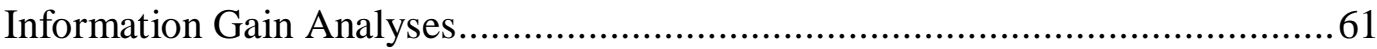

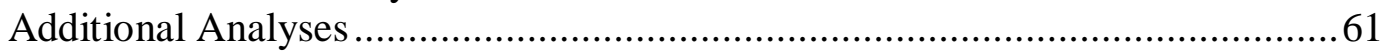

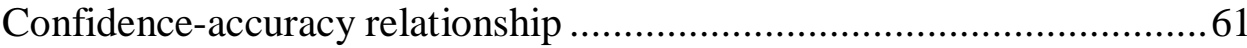

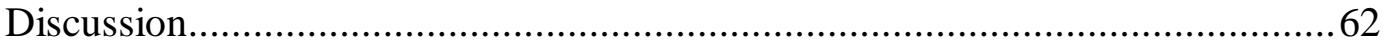

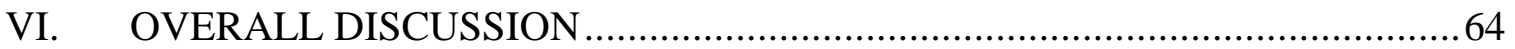

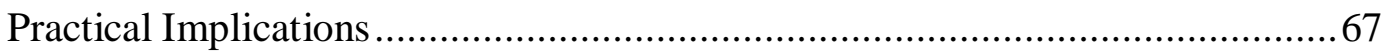

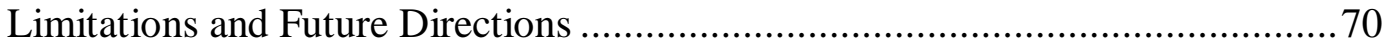

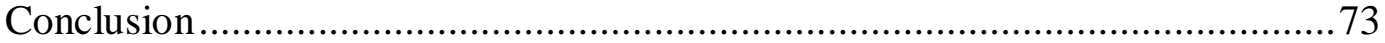

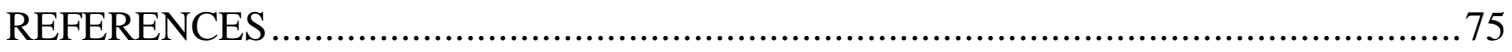

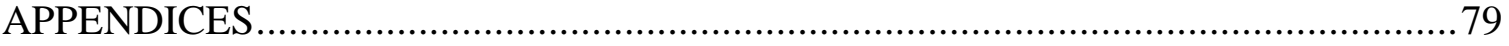

VITA 


\section{LIST OF TABLES}

TABLE

PAGE

1. Study 1 Target/Filler Similarity Ratings.

2. Study 1 Proportion of Choosing and Suspect Identifications for Overall Procedure Comparisons

3. Logistic Regressions Predicting Choosing and Suspect Identification Rates:

Field View vs. Lineup.

4. Logistic Regressions Predicting Choosing and Suspect Identification Rates:

Field View vs. Showup

5. Logistic Regressions Predicting Choosing and Suspect Identification Rates:

Lineup vs. Showup

6. Study 1 Proportion of Choosing and Suspect Identifications as a Function of Filler Similarity

7. Logistic Regressions Predicting Choosing and Suspect Identification Rates:

Lineups (Similar vs. Dissimilar).

8. Logistic Regressions Predicting Choosing and Suspect Identification Rates:

Field Views (Similar vs. Dissimilar)

9. Study 2 Proportion of Choosing and Suspect Identifications for Overall

Field View (Non-blind and Blind), Showup, Non-blind Field View, and

Blind Field View

10. Logistic Regressions Predicting Choosing and Suspect Identification Rates:

Overall Field View (Blind and Non-blind) vs. Showup

11. Logistic Regressions Predicting Choosing and Suspect Identification Rates: Non-blind Field View vs. Blind Field View

12. Logistic Regressions Predicting Choosing and Suspect Identification Rates: Non-blind Field View vs. Showup

13. Logistic Regressions Predicting Choosing and Suspect Identification Rates: Blind Field View vs. Showup. 


\section{INTRODUCTION}

In 1981, a young girl was attacked while waiting at her bus stop. She was raped, robbed, and shot, but managed to survive (O’Rourke, 2016). For various reasons, police believed that the attacker went to a particular high school in the area. Therefore, they took the girl to the high school, allowed her to walk around the halls, and gave her the task of determining whether the perpetrator was present at that high school. Ultimately, she identified a senior, Randall Ayers, as her attacker. The procedure that police used was defined in a recent report published by the National Academy of Sciences (NAS) as the field view procedure (National Research Council, 2014). As described in the NAS report, a field view is an identification procedure where a police officer escorts a witness to a particular location and gives the witness the task of determining whether the perpetrator is present in that location. According to the report, law enforcement officers will use this identification procedure when they do not have a suspect in mind but believe that the perpetrator frequents the location. We will refer to this procedure as an exploratory field view procedure. It is different from the traditional procedures in the literature, as little/no research has examined exploratory identification procedures - procedures where police do not have an a priori suspect.

Similarly, police may use this exploratory procedure without a particular location in mind. Instead, they may conduct the procedure by patrolling the area immediately after an incident has occurred. Imagine a situation whereby police arrive at a crime scene and gather information from the victim and/or any witnesses. After obtaining information regarding the perpetrator's description, it is likely police will drive around the surrounding neighborhoods to determine whether anyone matching the perpetrator's 
description is in the area. This is what happened the evening that Orlando Boquete was arrested for burglary and sexual assault ("The National Registry of Exonerations," 2016). Police officers patrolling the area asked a group of Cuban males to wait outside a convenience store while another officer escorted the victim to the store and asked her to determine whether she recognized anyone at the store as her attacker (Dwyer, 2007).

Both of these previous examples resulted in wrongful convictions. Although there may have been other factors involved in these cases, the mistaken identifications produced during this exploratory procedure contributed to the convictions of both Ayers and Boquete. It is likely that additional cases have resulted in wrongful convictions after a mistaken identification during an exploratory procedure. Currently, the Innocence Project has successfully assisted in the exoneration of 341 wrongfully convicted persons to date. In approximately $70 \%$ of those cases, at least one witness to the crime made an identification of the innocent suspect, making mistaken eyewitness identification the leading contributing factor of wrongful convictions in the United States (www.innocenceproject.org). The number of exoneration cases involving a mistaken identification during an exploratory procedure is unknown. However, we do know that the field view (1) is used by law enforcement officers (as indicated in the NAS report) and (2) has resulted in at least some mistaken identifications that have ultimately resulted in wrongful convictions (as illustrated in the examples above). Yet, the field view procedure has not been empirically examined to date. That is the main goal of the current project - to compare this exploratory procedure to the traditional identification procedures (i.e., the procedures used by law enforcement that are most commonly 
examined by researchers) and provide initial empirical data regarding identification accuracy rates elicited from the field view procedure.

\section{Traditional Identification Procedures}

Lineups. One of the most commonly used identification procedures is the lineup (Dysart \& Lindsay, 2007; Steblay, Dysart, Fulero, \& Lindsay, 2003). In a lineup procedure, the witness is shown a photo of the suspect along with several fillers (i.e., photos of people that should either match the description of the perpetrator or look similar to the suspect) and asked whether the person who committed the crime is present in those photos. Lineup photos can be presented to the witness simultaneously (i.e., all at one time) or sequentially (i.e., one at a time). In a simultaneous lineup, witnesses make a decision while viewing all lineup members and may choose a lineup member on the basis that the person is most like the perpetrator in relation to the other lineup members. In a sequential lineup, however, witnesses must make an absolute decision about each lineup member before viewing the next lineup member. However, they may be allowed to view the set of photos more than once depending on department guidelines. A lineup can also be conducted in person (i.e., with all lineup members present) but typically is not, as a live lineup would be much more time consuming to coordinate and the task of finding live fillers to match the witness's description of the perpetrator would be more difficult than using photos or videos (National Research Council, 2014).

The purpose of the fillers in a lineup is to protect an innocent suspect from witnesses who may be inclined to guess. Specifically, in a lineup, guesses may be distributed among all plausible choices. In other words, if there are five fillers and all the fillers (plus the suspect) look similar to the perpetrator, each person in the lineup should 
have a one in six chance of being selected by a guessing witness. Choosing one of the five fillers would not be harmful because they are known to be innocent, and the innocent suspect should only be chosen $1 / 6$ of the time. Because of this protection provided by fillers, lineups may be particularly beneficial when there is a long delay between the time of the crime and the identification procedure, as research shows that memory weakens over time (Ebbinghaus, 1885).

Showups. The other commonly used identification procedure is the showup (Dysart \& Lindsay, 2007; Steblay et al., 2003). A showup is an identification procedure where a witness is shown one person (i.e., the suspect) and asked whether that person is the perpetrator. This procedure is usually conducted in person and often near the location of the incident. When a suspect is apprehended soon after a crime occurs, it may be beneficial to conduct a showup because it is a less time consuming procedure than a lineup and the witness's memory for the event is still strong. Thus, it will assist police in quickly determining whether to continue investigating the current suspect or to pursue someone else. However, several real-world examples of wrongfully convicted suspects indicate that even in situations where there should not be a concern regarding witnesses' memory (e.g., there is a delay of only a few minutes between the time of the crime and the identification procedure), witnesses may still falsely identify an innocent suspect (Garrett, 2011). Mistaken identifications under such conditions may be explained by the major criticism of a showup - it is generally considered to be a suggestive procedure.

A showup is considered to be a suggestive procedure for several reasons. First, the procedure calls attention to the suspect; since there is only one person presented to the witness, it is obvious to the witness who the suspect is (Wells et al., 1998; Wells \& 
Quinlivan, 2009; Zimmerman, Austin, \& Kovera, 2012). This is especially problematic when witnesses trust that the police have arrested the correct person (Behrman \& Davey, 2001). Second, the manner in which the suspect is presented in a showup may be suggestive of the suspect's guilt (Garrett, 2011). For instance, although it is warned against conducting a showup with the suspect in the back of a police car or in handcuffs, the warnings may not always be followed in situations where safety may be an issue (National Research Council, 2014). Furthermore, the location that the showup is administered may also increase the suggestiveness of the procedure (Agricola, 2009). Often a suspect will be apprehended near the crime scene and will be shown to the witness in that location; other times, a showup may be administered at the police station or even with the suspect in a jail cell. A final point, related to the first, is that a showup can be unintentionally biased by the administrator. Just as the witness knows the person he/she is viewing is the suspect, so does the showup administrator; it is impossible for the officer administering the showup to be blind to the identity of the suspect. All of these problems should tend to increase the likelihood of false identifications; indeed, the literature on showups tends to support the idea that the showup is a less reliable procedure than the lineup (Wells, Yang, \& Smalarz, 2015).

Lineups vs. showups. Behrman and Davey (2001) conducted an archival study analyzing 271 cases, involving 349 crimes, and with varying levels of evidence against the suspect. Data indicated that showups produced a much higher rate of suspect identifications than lineups (approximately 76\% and 48\%, respectively), regardless of the amount of evidence against the suspect. One problem with archival data, however, is that ground truth cannot be ascertained, meaning that we do not know which suspects are 
truly guilty and which suspects are actually innocent. Thus, it is impossible to know true accuracy rates within these studies. Nonetheless, the findings are still valuable. Behrman and Davey's analysis indicates that unless there was a much higher percentage of guilty suspects in the showups examined than in the lineups examined, something about the showup procedure itself leads witnesses to choose the suspect.

Steblay et al. (2003) conducted a meta-analysis of 12 experimental studies comparing lineups and showups. Results indicated that lineups and showups produced a similar rate of correct identifications in target present conditions but that showups produced significantly fewer errors in target absent conditions. Importantly, however, while an error in a target-absent showup necessarily means that the witness falsely identified an innocent suspect, an error rate in a target-absent lineup could mean either that the witness falsely identified an innocent suspect or that a witness identified a filler. Since identifying a filler is not harmful (because fillers are known to be innocent), as identifying an innocent suspect would be, Steblay et al. re-analyzed five of the studies that allowed examination of suspect and filler identifications in the lineups separately. After removing filler identifications from the analyses, the rate of false identifications was comparable between lineups and showups. However, when the suspect closely matched the description of the perpetrator, false identifications of the suspect were much greater for showups than for lineups. Overall, the studies examined in the meta-analysis indicate that showups may be most harmful when police have a suspect who is innocent but matches the description of the perpetrator.

In most of these studies, however, one real world issue is often overlooked. To avoid confounding variables, most studies compare lineups and showups while keeping 
other variables consistent. Yet, it is important to consider that in the real world, it makes sense to conduct a showup when a suspect is apprehended shortly after a crime occurs but a lineup when there is a delay between the time of the crime and the apprehension of a suspect. Wetmore et al. (2015) examined the hypotheses that (1) viewing an immediate showup will lead to equivalent or greater identification accuracy than viewing a delayed lineup and that (2) showups will lead to greater identification accuracy than biased lineups but poorer identification accuracy than unbiased lineups. In the study, participants viewed a mock crime, completed a short filler task, and then completed an identification task with a showup or lineup either after the filler task or 48 hours after viewing the mock crime video. In the lineup conditions, participants viewed either a fair or biased lineup. Results of the study did not support either of the hypotheses. First, showups never produced more correct identifications than lineups in either of the delay conditions. The correct identification rate for showups was equivalent to that of fair lineups but lower than biased lineups. Second, and perhaps most interestingly, although the rate of false identifications was higher for biased lineups than fair lineups, showups produced more false identifications than both fair and biased lineups. Wetmore et al. (2015) concluded that showups are never more reliable than lineups.

A more recent study revealed yet another potential advantage of the lineup procedure in comparison to the showup procedure (Charman \& Kavetski, in progress). Specifically, it appears that witnesses participating in a showup procedure may be particularly susceptible to suggestive influences. The study examined how witnesses' beliefs about law enforcement officers' beliefs influence their decisions in the showup procedure. We tested the hypothesis that suggestive information (i.e., belief that police 
officers believe the suspect is guilty) would either (a) increase choosing rates for both showups and lineups but that the increased choosing rate for lineups would be siphoned off into filler choices, or (b) increase choosing just in the showup condition. Either result was expected to produce greater rates of false identifications for showups than for lineups.

Participants in the study were first informed of a fictitious new legal policy whereby the first officer at the scene of a crime is required to take photos of the area and all the people in the area. Then, participants were made aware of a crime that was supposedly caught on a cell phone camera by a student who was sitting in her car in the parking lot where the crime occurred. Participants were told that the researchers wanted to use the footage to test the effectiveness of this new policy and to determine whether it helped solve crimes. Thus, participants were to act as the witness; they watched the mock crime video and were given information that police took photos of several people in the area. They were informed either that police (1) found a person in the area behaving suspiciously and believed the evidence pointed to that person (i.e., suspect instructions), or (2) did not believe that evidence pointed to any suspect at the time (i.e., bystander instructions). Then, participants viewed either a target present or target absent showup or lineup. In the target absent conditions, the perpetrator was replaced with an a priori innocent suspect. Participants were asked to make an identification decision, provide confidence ratings, and complete additional questionnaires.

Results revealed that overall (i.e., collapsed across instruction type), showups produced a significantly higher rate of false identifications than lineups (19.4\% vs. $7.5 \%$, respectively). More importantly, the suspect instruction (c.f., the bystander instruction) 
only increased false identifications from showups; the suggestive information did not affect choosing rates, correct identifications, or false identifications in the lineup condition. They also had no influence on suspect identifications in the target present conditions for showups. Thus, this study indicates that lineups may be "better" than showups partly because witnesses who participate in a lineup are less susceptible to suggestive influences than witnesses who undergo the showup procedure due to the presence of fillers. For instance,

\section{Comparison of the Field View to the Traditional Procedures}

The field view procedure contains similar aspects to both the lineup and the showup procedures. Lineups contain several fillers that serve the purpose of protecting an innocent suspect from a witness who may be inclined to guess. Similarly, the field view procedure is likely to take place in an area where several people are located and ultimately escapes the major criticism of a showup - that it is a suggestive procedure whereby the witness and administrator always know the identity of the suspect. In fact, the officer conducting the exploratory field view is always, by definition, blind to the status of a suspect, as there is not an a priori suspect at all. Thus, the administrator of the procedure has no knowledge that could cause him/her to bias the witness's decision. A showup, on the other hand, cannot ever be administered blind. Like a showup, however, the field view can be conducted soon after the crime has occurred, allowing for the identification procedure to take place while the witness's memory for the event is still strong. Additionally, this advantage allows officers to quickly assess whether to pursue a suspect elsewhere. Finally, similar to a showup, the field view is conducted in person, 
potentially offering the witness additional cues, such as gait, posture, or demeanor, when making his/her decision that are not available via a photo array (i.e., a lineup).

Considering these similarities of the field view to the traditional procedures, it appears that the field view embodies the most beneficial aspects of each procedure. However, it is also important to understand the differences between the three procedures. Most notably, in an exploratory procedure, there is not an a priori suspect. In other words, people who happen to be in the area are not known to be innocent, as fillers are in a lineup. Therefore, a witness could make a positive identification of anyone present and that person would come under suspicion. As such, the "fillers" in a field view procedure do not serve the same purpose as in a lineup.

Study 1 first reviews the literature on lineup fillers and then utilizes a controlled, lab-based methodology to examine whether filler similarity in a field view procedure affects identification accuracy in the same manner as in lineups. 


\section{STUDY 1}

\section{Filler Similarity}

The purpose of fillers in a lineup is to protect an innocent suspect from being identified (Charman \& Wells, 2007). To do so, fillers should be similar enough to the suspect that the suspect does not stand out. However, in order to still obtain identifications of a guilty suspect, the fillers should also not be "too similar" to the suspect (Fitzgerald, Price, Oriet, \& Charman, 2013). Several studies have focused on the best method for choosing fillers (Luus \& Wells, 1991; Tunnicliff \& Clark, 2000; Wells, Rydel, \& Seelau, 1993). Specifically, they examine whether it is better to choose fillers based on their match to the description of the perpetrator or on their similarity to the suspect. For instance, Wells et al. (1993) examined identification accuracy rates when the fillers in the lineup were similar to the suspect, matched the description of the perpetrator, or did not match the description of the perpetrator except on characteristics of race and gender. Results of the study indicated that correct identification rates when the fillers did not match the description were comparable to correct identification rates when the fillers matched the description, but were lowest when the fillers resembled the suspect. Results also revealed that false identification rates were highest when the fillers did not match the description of the perpetrator. Overall, the study suggests that the best procedure for increasing correct identifications when the perpetrator is present in the lineup and reducing false identifications when the perpetrator is not present in the lineup may be to choose fillers on the basis that they match the description of the perpetrator.

Other studies have failed to find an advantage of choosing fillers based on their match to the description of the perpetrator and have even suggested there may be a slight 
advantage to choosing fillers based on their similarity to the suspect (Tunnicliff \& Clark, 2000). In two studies, Tunnicliff and Clark first asked police officers and students to create lineups by choosing fillers based either on their match to a description of the perpetrator or on their similarity to the suspect. Then, participants in the studies either viewed a staged event or several photos. After a delay, they were asked to make an identification decision from one of the lineups that either contained the suspect or did not. Results indicated that filler selection strategy (match-description or match-suspect) did not significantly affect correct or false identification rates. However, when fillers were chosen on the basis of their match to the suspect, lineups produced more correct rejections from target absent lineups than when fillers were chosen on the basis of their match to the description of the perpetrator. This means that match-description lineups produced more filler identifications in the target absent condition than match-suspect lineups.

However, if fillers are chosen because of their similarity to the suspect, another issue emerges: how similar is similar enough? Fitzgerald et al. (2013) conducted a metaanalysis including 17 studies to examine how fillers affect identification accuracy when they are of low, moderate, and high similarity to the suspect. Results of the meta-analysis indicated that low-similarity fillers resulted in the highest rates of correct and false identifications. Additionally, moderate similarity fillers produced more false identifications than high-similarity fillers. Finally, the results revealed that identifications of the suspect were more diagnostic of the suspect's guilt when the degree of similarity between the fillers and the suspect was greater. Overall, the meta-analysis suggests that 
the greater the similarity of the fillers to the suspect, the better the fillers serve their purpose of protecting innocent suspects.

Furthermore, in addition to accuracy rates, witnesses' confidence in their identification decisions may also be affected if fillers are too dissimilar to the suspect (Charman, Wells, \& Joy, 2011). A series of studies tested and found support for the idea that including highly dissimilar fillers in a lineup inflates witnesses' confidence in their identification decisions, regardless of the accuracy of those decisions. This finding is extremely important for a mistakenly identified innocent suspect, as triers of fact (i.e., jurors) are likely to more strongly believe a confident witness than a witness who is uncertain (Wells, Ferguson, \& Lindsay, 1981).

In sum, although the manner of choosing fillers has been debated and the findings regarding how to choose fillers are mixed, there is little debate that fillers can serve their purpose of protecting an innocent suspect if the ones chosen are "similar enough."

\section{Purpose}

To date, no research has empirically tested the field view procedure. However, because the field view is used by law enforcement, it is important to understand how the procedure may influence witnesses' decisions. Thus, the main goal of this study is to provide initial data regarding the rates of identification accuracy produced from a field view in comparison to a lineup and a showup.

Additionally, the field view procedure embodies some aspects of both the lineup and showup procedures, but also involves some critical differences. For instance, law enforcement has no control over the people in the area during a field view procedure, as they would have control over fillers in a lineup. In other words, they cannot control 
whether the people in the area match the description of the perpetrator, and they cannot control their level of similarity to one another. In fact, it is likely that a field view will include people of varying similarity to the perpetrator and to each other. As such, it is important to consider how this exploratory procedure fares across a range of similarity of fillers. Thus, the second goal of Study 1 is to examine how filler similarity affects identification accuracy in the field view procedure, by comparing a field view that contains fillers rated as similar to the perpetrator to a field view that contains fillers rated as dissimilar to the perpetrator.

\section{Hypotheses}

First, we expect that the field view procedure will fare similarly to the traditional procedures in regards to correct identifications. However, because there is no a priori suspect in the field view condition, an identification of anyone except the actual perpetrator would be considered a false identification (in contrast to a filler identification from a lineup, which is known to be incorrect); consequently, we expect the field view procedure will result in more false identifications than either the lineup or the showup procedures.

More specifically, we expect that (1a) witnesses will choose equally often from field views as from lineups, but that some of the choices made in lineups, particularly in the target absent condition, will be distributed among the known innocent fillers. Thus we expect field views will (1b) produce equal correct identifications as lineups, but will (1c) produce a greater rate of false identifications than lineups.

Further, we expect that (2a) witnesses will choose more from field views than from showups. However, although we expect that (2b) correct identifications will be 
equal for field views and showups, we expect that, since all identifications from a field view may be treated by police as suspect identifications, (2c) false identifications will be higher for field views than for showups.

Based on past research, we expect that (3a) witnesses will choose more from lineups than from showups, and that (3b) the correct identification rates will be equal for lineups as for showups. Again, since lineup choices may be distributed among the known innocent fillers, particularly in the target absent condition, whereas all identifications from a showup are necessarily of the suspect, we expect that (3c) lineups will result in fewer false identifications than showups.

Furthermore, we expect that filler similarity will affect identifications in the lineup procedure. Specifically, we expect that (4a) witnesses will choose equally often from lineups that contain dissimilar fillers as from lineups that contain similar fillers. However, we expect that dissimilar fillers will result in more suspect identifications than similar fillers, and thus (4b) dissimilar fillers will produce more correct identifications than similar fillers in lineups. Based on past research, we also expect that $(4 \mathrm{c})$ dissimilar fillers will result in more false identifications of the innocent suspect than similar fillers for lineups.

Similarly, we expect that (5a) witnesses will choose equally often from field views that contain dissimilar fillers as from field views that contain similar fillers. However, we expect to find that dissimilar fillers will increase identifications of the person that bears that strongest resemblance to the perpetrator. Because the person who looks most similar to the perpetrator in the target present conditions is in fact the perpetrator, we expect that (5b) dissimilar fillers will produce more correct identifications 
than similar fillers in the field view. On the other hand, we expect that (5c) dissimilar fillers and similar fillers will produce equal false identifications in the field view. The reason we expect to find no difference in false identification rates is because dissimilar fillers should produce more choices of one person in particular, but similar and dissimilar fillers will produce equal choices overall (i.e., choices in the similar fillers condition will be dispersed among all plausible choices), and importantly, any choice in a target absent field view is considered a false identification.

\section{Method}

Participants. Participants included 395 undergraduate students from a large southeastern university. The sample was primarily female (70.13\%) and Hispanic (60.0\%; 18.2\% African American; 12.4\% Caucasian; 3.8\% Asian; 5.6\% Other). The mean age of participants was 21.22 years old $(S D=4.15)$. All participants were recruited via the university's online recruitment system and were given either course credit or extra credit for their participation. The study was conducted via a lab computer, and participants were run one at a time.

Design. After viewing a mock crime, participants were randomly assigned to be administered either a videotaped field view with five fillers that were rated as similar to the perpetrator, a videotaped field view with five fillers that were rated as dissimilar to the perpetrator, a videotaped showup (i.e., containing no fillers), or a lineup with five fillers that were rated as similar to the perpetrator or dissimilar to the perpetrator (control conditions). Thus, the study was a 2 (Filler similarity: Similar vs. Dissimilar) x 2 (Identification procedure: Field view vs. Lineup) x 2 (Target presence: Target present (TP) vs. Target absent (TA)) + 2 (TP Showup vs. TA Showup) between-subjects design. 
The main dependent variables were choosing rates and the accuracy of the identification decisions. We also examined confidence in the identification decision and several other secondary dependent variables. All research assistants were blind to the condition that participants received to reduce the chances of administrator bias.

\section{Materials.}

Mock crime videos. Participants were randomly assigned to receive one of two mock crime videos. The videos depicted a girl on the fifth floor of the university's library standing up from a cubicle, walking one cubicle over, reaching into a purse that was left there, and taking out a debit card, before turning and walking away. The video was approximately 30 seconds long and showed the perpetrator's face from various angles. The two videos were exactly the same, aside from the perpetrator.

Recruitment of perpetrators and fillers. Two perpetrators were used for this study in order to have an a priori innocent suspect. Each perpetrator served as the other's replacement in the target absent conditions. To recruit the perpetrators and fillers, announcements were made in several courses at the end of the semester asking students to assist with materials for a research project in exchange for course credit. We specifically asked for female students and were interested in those that were - or could appear - to be Hispanic. Because the majority of the students in the courses were Hispanic females, this combination gave us more options than other potential combinations (i.e., African American males, Asian females, etc.).

Three people rated the similarity of each pair of potential perpetrators on a scale from 1 (Extremely dissimilar) to 7 (Extremely similar). The two perpetrators and fillers were chosen based on these similarity ratings. The pair who received the highest average 
similarity rating to each other (i.e., 6.00) was chosen as the perpetrators. Then, the five people with the highest similarity ratings to both targets were chosen as the fillers for the similar procedure conditions, while the five people with the lowest similarity ratings to both targets were chosen as the fillers for the dissimilar procedure conditions. The average rating of the similar fillers to Target 1 was 4.53 . The average rating of the dissimilar fillers to Target 1 was 2.46, resulting in a significant difference of 2.07 between the two averages of similar and dissimilar fillers for Target $1, t(28)=3.76, p=$ .001. The average rating of the similar and dissimilar fillers to Target 2 was 3.73 and 2.40 , respectively - a significant difference of 1.33 between the two averages, $t(28)=$ $2.33, p=.027$. For similarity ratings of each filler to each target, and each filler to each other filler, see Table 1.

Field view videos. To control the similarity of fillers and collect data in a timely manner, videotaped field views were used for Study 1. The video was filmed walking around a section on the second floor of the university's library. The manner in which the video was filmed was intended to give the witness the sense that he/she was walking around the location and participating in an actual field view. Specifically, the video began with a view of all five fillers and the target from a distance. They all sat around tables in the library and pretended to engage in schoolwork as they sat there. Then, the video moved closer and captured a view of each person's face in passing. The target was encountered in the middle of the video (i.e., position 4). The targets were asked to wear matching clothing with no identifying marks (i.e., white shirt and jeans). However, to simulate an actual field view, the fillers were told to dress as they would on any regular day. To ensure that potential differences in accuracy rates between similar and dissimilar 
conditions were not due to differences in behavior between similar and dissimilar fillers, both videos for one target were filmed first, followed by both videos for the second target. In other words, after the video with Target 1 and the similar fillers was filmed, the dissimilar fillers replaced the similar fillers, mimicking their behavior (i.e., to minimize differences). Then the process was repeated with Target 2 . Thus, a total of four field view videos were created. The videos were approximately 43 seconds long.

Showup clips. To keep media type consistent, videos were also used for the showups. Rather than film additional videos, and to avoid potential confounds (i.e., to ensure there were no differences between the behavior of the target in the field view and showup conditions that could influence identification decisions), the field view videos were edited for use in the showup condition. Specifically, the parts of the videos that included the fillers were edited out of the videos so that the showup video clip began immediately before viewing the target and ended immediately after scanning away from the target. A total of four showup video clips were created (one from each of the four videos). Participants who were randomly assigned to the showup condition were also randomly assigned to see one of the two video clips of one of the two targets (i.e., depending on whether they were assigned to a target present or target absent condition). The showup video clips were approximately 6 seconds long.

Lineups. Lineups were created using still image shots of the targets and fillers from the field view videos. Although this method differs from a 'typical' lineup that includes straight-on shots of the lineup members' faces where they are all either wearing the same clothing or not showing clothing in the photos, we used this method in order to avoid confounding clothing with procedure. For example, if we created a typical lineup 
and there were more suspect identifications from the field view than from the lineup, we would not be able to determine whether the effects were due to the procedure itself or from a clothing bias in the field view condition (i.e., because the perpetrator and innocent suspect were wearing similar clothing in the field view but not in the lineup). A total of four lineups were created (one from each of the four videos). The fillers and target were presented simultaneously and in the same order as viewed in the field view condition.

Follow-up questionnaires. Follow-up questionnaires were created to examine participants' experience and beliefs about the identification procedures. We also questioned participants about the expectations they had prior to viewing the identification procedure (i.e., whether they expected the perpetrator to be present in the identification task) and how they made their decisions.

Procedure. After arriving to the lab and signing a consent form, participants were randomly assigned to view one of the two mock crime videos. Then, they completed a 15 minute filler task. Next, participants were randomly assigned to participate in one of the identification procedures (i.e., field view with similar fillers, field view with dissimilar fillers, showup, lineup with similar fillers, or lineup with dissimilar fillers) where the perpetrator was either present or absent in the procedure. Participants in the field view conditions were informed that they were going to view a videotape of people in the library and that the person they saw in the mock crime video may or may not be present in the video (i.e., unbiased instructions). They were told that it is their job to determine whether the person is present in the video and that they are allowed to pause, rewind, and watch the video as many times as they like until they have made a decision. The purpose of this instruction was to mirror an actual field view, as witnesses participating in an 
actual field view procedure would, presumably, be allowed to view the scene and the people in the location for as long as they like. The showup and lineup instructions were created to mimic the field view instructions as closely as possible to avoid confounding instructions with the procedure. For instance, participants in the showup conditions were told they were going to view a video clip of someone in the library but were still given unbiased instructions and were told that they could pause, rewind, and watch the clip as many times as they like. Participants in the lineup conditions were told that they were going to view photos of several people in the library, given unbiased instructions, and informed that they could view the photos for as long as they like until they have made a decision. For full instructions, see Appendix A.

Participants in the field view conditions who made a decision before viewing the entire video were asked to watch the video until the end. The purpose of this was to ensure they saw all fillers. Although witnesses in an actual field view may not look at every person in that area, it was essential for this study that participants saw all the fillers because (aside from the procedure manipulation), filler similarity was the main variable of interest. After the identification task, participants were asked to rate their confidence in that identification decision on a scale from 0 (Not at all confident) to 100 (Extremely confident). Then, participants completed a demographic questionnaire regarding their age, gender, ethnicity, and education, along with other follow-up questionnaires (see Appendix B). Finally, they were debriefed, thanked for their participation, and dismissed. 


\section{RESULTS AND DISCUSSION}

\section{Data Excluded from Analyses}

A total of 12 participants were excluded from the analyses for various reasons: Six were excluded because the research assistant failed to stop the filler task after 15 minutes; four were excluded due to other research assistant mistakes (e.g., straying from the instructions and suggesting whether the participant should make an identification); one participant was excluded after pausing the mock crime video on the perpetrator to ask the research assistant questions; one final participant was excluded because of a computer malfunction.

Sixteen participants responded that they know or recognize either the target or one of the fillers. In many studies, personally knowing someone who is part of the study would be grounds to exclude that participant. However, in a field view, it is not unlikely that the witness recognizes one or more of the people in the area. For instance, consider the case where officers walked the female student around a local high school. It is likely she knew one or more of the people she encountered when walking through the hallways. Thus, the data were analyzed with and without these 16 participants and because no significant differences emerged, only the analyses including these 16 participants are reported. The following analyses include data from 383 participants.

\section{Comparison of the Exploratory Field View to the Traditional Procedures}

Hypotheses 1-3 were tested using logistic regression analyses to compare choosing and accuracy rates for field views vs. lineups, field views vs. showups, and lineups vs. showups. For each comparison, choosing rates were first regressed onto procedure, target presence, and the interaction of procedure and target presence. Then, 
suspect identifications were regressed onto procedure, target presence, and the interaction of the two variables. Chi-square analyses were conducted to further examine differences in correct and false identifications for each comparison (see Table 2 for all choosing and suspect identification rates and Tables 3-5 for logistic regression analyses).

Furthermore, diagnosticity of suspect identifications was calculated and compared across identification procedures. Diagnosticity is used to determine the likelihood that a suspect is guilty if that suspect is identified (Wells \& Lindsay, 1980). More specifically, diagnosticity is calculated as the percentage of correct identifications divided by the percentage of false identifications elicited from the procedure. Thus, the larger the diagnostic value, the greater likelihood that an identified suspect is guilty.

Field view vs. lineup. As expected (Hypothesis 1a), results from the logistic regression indicated that procedure type had no effect on choosing rates. In other words, participants chose (i.e., made an identification) as often in the field view (54\%) as they did in the lineup (52\%), $\beta=0.00$, Wald $\chi^{2}(1)=0.00, p=1.00$. Results also indicated that participants made more choices overall in field views and lineups that contained the perpetrator $(71 \%)$ than field views and lineups that did not contain the perpetrator $(36 \%$; $\beta=1.52$, Wald, $\left.\chi^{2}(1)=19.07, p<.001\right)$. The interaction effect of procedure type and target presence was not significant, $\beta=-0.13$, Wald, $\chi^{2}(1)=0.07, p=.793$.

Furthermore, the effects of procedure and target presence on suspect identifications were both significant, such that overall, participants identified the suspect more often in the field view than the lineup (50\% and $34 \%$, respectively; $\beta=-1.34$, Wald, $\left.\chi^{2}(1)=10.49, p=.001\right)$, and more often in target present conditions than target absent conditions (both procedures; $60 \%$ and $24 \%$, respectively; $\beta=1.16$, Wald, $\chi^{2}(1)=11.75$, 
$p=.001)$. However, the interaction effect of procedure and target presence was also marginally significant $\left(\beta=1.00\right.$, Wald, $\left.\chi^{2}(1)=3.56, p=.059\right)$. Further analyses revealed that the effect of procedure on suspect identifications was not significant in the target present conditions. In other words, results supported our prediction (Hypothesis 1b) that the field view would produce equal correct identifications as the lineup (64\% and 56\%, respectively; $\left.\chi^{2}(1)=1.00, p=.317\right)$.

On the other hand, analyses revealed that field views did produce more suspect identifications than the lineup in target absent conditions, also as expected (Hypothesis 1c). In other words, field views produced more false identifications than lineups (36\% and $13 \%$, respectively; $\left.\chi^{2}(1)=11.27, p=.001\right)$.

Overall, results indicate that field views and lineups produce an equal rate of choosing, and an equal rate of correct identifications, but because many of the choices in the target absent lineups were distributed among the known innocent fillers, whereas any choice in the target absent field view was considered a false identification, field views produced more false identifications than lineups.

Finally, the diagnostic value of the field view procedure was 1.78 , meaning that a witness in this condition is 1.78 times more likely to identify the perpetrator when she was in the identification procedure than to identify an innocent person when the perpetrator was not present in the identification procedure. The diagnostic value of the lineup procedure was 4.31. Subsequent analyses indicated that the difference in diagnosticity rates between the field view and lineup procedures was not significant, $z=1.68, p=.093$ using a two-tailed test. This means that although the field view produced significantly more false identifications than the lineup, a suspect identification 
from a lineup is no more indicative of that suspect's guilt than a suspect identification from a field view.

Field view vs. showup. Consistent with our expectations (Hypothesis 2a), results from the logistic regression indicated that procedure type significantly affected choosing rates. Overall, participants chose more often in the field view (54\%) than they did in the showup (35\%), $\beta=-2.34$, Wald $\chi^{2}(1)=9.38, p=.002$. Results also indicated that participants made more choices overall in target present field views and showups (70\%) than target absent field views and showups $\left(26 \% ; \beta=1.52\right.$, Wald $\chi^{2}(1)=19.07$, $p<.001)$. Additionally, the interaction effect of procedure and target presence was also significant $\left(\beta=2.05\right.$, Wald $\left.\chi^{2}(1)=5.47, p=.019\right)$, revealing that the field view only produced more choices than the showup in the target absent conditions (36\% and 5\%, respectively; $\left.\chi^{2}(1)=12.91, p<.001\right)$ and not in the target present conditions $(72 \%$ and $66 \%$, respectively; $\left.\chi^{2}(1)=0.46, p=.496\right)$.

Because a choice in a target present or target absent showup, and a choice in a target absent field view are equivalent to their corresponding suspect identification rates, results of the logistic regression model predicting suspect identifications were very similar to that of the model predicting choosing. However, because a choice in a target present field view does not necessarily indicate a suspect identification, proportions vary slightly between the two models. Specifically, the effects of procedure and target presence on suspect identifications were both significant. Overall, participants identified the suspect more often in the field view than the showup (50\% and 35\%, respectively; $\beta=-2.34$, Wald $\chi^{2}(1)=9.38, p=.002$ ), and more often in target present conditions than target absent conditions ( $65 \%$ and $26 \%$, respectively; $\beta=1.16$, Wald $\chi^{2}(1)=11.75$, 
$p=.001)$. The interaction effect of procedure and target presence was also significant $\left(\beta=2.05\right.$, Wald $\left.\chi^{2}(1)=5.47, p=.019\right)$, revealing that the effect of procedure on suspect identifications was not significant in the target present condition. In other words, results supported our prediction (Hypothesis $2 b$ ) that correct identifications were equal for field views and showups (64\% and 66\%, respectively; $\left.\chi^{2}(1)=0.04, p=.851\right)$.

The significant interaction also revealed that the effect of procedure on suspect identifications was significant for target absent conditions, providing support for our prediction (Hypothesis 2c) that field views would result in significantly more false identifications than showups ( $36 \%$ and $5 \%$, respectively; $\chi^{2}(1)=12.91, p<.001$ ).

Overall, results for the field view/showup comparison indicate that field views produce more choices than showups, albeit only in the target absent conditions, and an equal rate of correct identifications. Because choices in a showup and in a target absent field view are equivalent to their respective rates of false identifications, field views produced more false identifications than showups.

The diagnostic value of the field view procedure (1.78) was compared to that of the showup (13.2). Analyses indicated that this difference in diagnosticity rates was significant, $z=3.14, p=.002$, using a two-tailed test, meaning that a suspect identification is significantly more indicative of that suspect's guilt when made during a showup procedure than during a field view procedure.

Lineup vs. showup. Results of the logistic regression supported our prediction (Hypothesis 3a) that lineups would produce more choices than showups. Overall, participants chose more often in the lineup than in the showup (52\% and 35\%, 
respectively; $\beta=2.34$, Wald $\chi^{2}(1)=9.38, p=.002$ ), and more often in target present conditions than target absent conditions (both procedures; $68 \%$ and 26\%, respectively; $\beta=3.57$, Wald $\left.\chi^{2}(1)=19.81, p<.001\right)$. Similar to the field view/showup comparison, the interaction effect of procedure and target presence on choosing was also significant, $\beta=2.34$, Wald $\chi^{2}(1)=9.38, p=.002$, indicating that lineups produced more choices than the field view in target absent conditions $\left(36 \%\right.$ and $5 \%$, respectively; $\chi^{2}(1)=12.91$, $p<.001)$, but an equal rate of choices in target present conditions (69\% and 66\%, respectively; $\left.\chi^{2}(1)=0.15, p=.702\right)$.

The effect of procedure (which significantly predicted choosing) was not significant on suspect identification rates $\left(\beta=1.00\right.$, Wald $\left.\chi^{2}(1)=1.56, p=.212\right)$. Participants identified the suspect as often in lineups (34\%) as in showups (35\%). Further analyses revealed support for our prediction (Hypothesis 3b) that lineups and showups would produce an equal rate of correct identifications (56\% and 66\%, respectively, $\left.\chi^{2}(1)=1.00, p=.317\right)$

However, contrary to our expectations that lineups would produce fewer false identifications than showups (Hypothesis 3c), results indicated that lineups and showups also produced an equal rate of false identifications (13\% and 5\%, respectively, $\left.\chi^{2}(1)=1.67, p=.196\right)$.

Overall, results indicate that lineups produced more choices than the showup, but only in the target absent condition and that lineups and showups produced an equal rate of correct identifications. However, because some lineup choices, particularly in the target absent condition, were filler choices, the lineup and showup produced an equal rate 
of false identifications. Importantly, lineups produced a choosing rate of $36 \%$, but a suspect identification rate of only $13 \%$ in target absent conditions.

The diagnostic value of the lineup procedure (4.31) was compared to that of the showup procedure (13.2). Analyses indicated that this difference in diagnosticity rates was not significant, $z=1.76, p=.078$ using a two-tailed test, meaning that a suspect identification from a showup and a suspect identification from a lineup are equally indicative of that suspect's guilt.

\section{Effect of Filler Similarity}

Hypotheses 4 and 5 were tested using logistic regression analyses to compare the effect of filler similarity on choosing and accuracy rates for field views and lineups. For each procedure, choosing rates were first regressed onto filler similarity, target presence, and the interaction of filler similarity and target presence. Then, suspect identifications were regressed onto filler similarity, target presence, and the interaction of the two variables. Chi-square analyses were conducted to further examine differences in correct and false identifications resulting from the effects of filler similarity for each procedure (see Table 6 for all choosing and suspect identification rates and Tables 7 and 8 for logistic regression analyses). Finally, diagnosticity of suspect identifications was calculated and compared across levels of filler similarity for each procedure.

Lineup. Consistent with our prediction that witnesses would choose equally often from lineups that contained dissimilar fillers as from lineups that contained similar fillers (Hypothesis 4a), results of the logistic regression indicated that filler similarity had no effect on choosing rates in lineups. In other words, similar and dissimilar fillers resulted 
in an equal rate of choosing ( $55 \%$ and $49 \%$, respectively; $\beta=-0.23$, Wald $\chi^{2}(1)=0.46, p$ $=.496)$.

Filler similarity also had no effect on rates of suspect identifications in lineups, meaning that similar and dissimilar fillers resulted in an equal rate of suspect identifications ( $32 \%$ and $36 \%$, respectively; $\beta=1.33$, Wald $\chi^{2}(1)=2.58, p=.108$ ). As such, our prediction that dissimilar fillers would produce more correct identifications than similar fillers in a lineup (Hypothesis 4b) was not supported. Lineups with similar fillers and lineups with dissimilar fillers produced an equal rate of correct identifications (54\% and $59 \%$, respectively; $\left.\chi^{2}(1)=0.20, p=.654\right)$.

Also inconsistent with our hypothesis that dissimilar fillers would produce more false identifications than similar fillers in a lineup (Hypothesis 4c), results indicated that lineups with similar fillers and lineups with dissimilar fillers produced an equal rate of false identifications ( $6 \%$ and $19 \%$, respectively; $\left.\chi^{2}(1)=2.87, p=.090\right)$. Importantly, however, similar fillers resulted in a $40 \%$ choosing rate in the target absent condition, but a false identification rate of only $6 \%$. Dissimilar fillers resulted in a $33 \%$ choosing rate in the target absent condition, and false identification rate of $19 \%$.

Overall, results indicate that lineups with similar fillers and lineups with dissimilar fillers produced equal rates of choosing, equal rates of correct identifications, and equal rates of false identifications.

The diagnostic value of the lineup with similar fillers procedure (9.00) was compared to that of the lineup with dissimilar fillers procedure (3.11). Analyses indicated that the difference in diagnosticity rates between the two procedures was not significant, 
$z=0.94, p=.347$, using a two-tailed test. This suggests that a suspect identification is equally indicative of that suspect's guilt when elicited from a lineup that contains dissimilar fillers as it is from a lineup that contains similar fillers. This finding, however, contradicts the results of Fitzgerald et al.'s (2013) meta-analysis of filler similarity studies, which suggests that a suspect identification is more indicative of that suspect's guilt when the degree of similarity between fillers and the suspect is greater.

Field view. The effects of filler similarity produced the same pattern of results for the field view procedure as in the lineup procedure. Specifically, filler similarity had no effect on choosing rates in field views, providing support for our prediction (Hypothesis 5a), and revealing that similar and dissimilar fillers produced an equal rate of choosing (53\% and 54\%, respectively; $\beta=0.16$, Wald $\left.\chi^{2}(1)=0.12, p=.734\right)$.

Results also indicated that filler similarity had no effect on rates of suspect identifications in field views, as participants identified the suspect as often from the field view with similar fillers as from the field view with dissimilar fillers (48\% and $51 \%$, respectively; $\beta=0.16$, Wald $\left.\chi^{2}(1)=0.12, p=.734\right)$. Further analyses revealed that similar and dissimilar fillers produced an equal rate of correct identifications $(65 \%$ and $63 \%$, respectively; $\left.\chi^{2}(1)=0.01, p=.908\right)$, despite our prediction that dissimilar fillers would produce more correct identifications than similar fillers in the field view (Hypothesis 5b).

However, consistent with our prediction (Hypothesis 5c), dissimilar fillers and similar fillers produced an equal rate of false identifications in the field view (34\% and $38 \%$, respectively; $\left.\chi^{2}(1)=0.12, p=.734\right)$. 
Overall, results indicate that field views with similar fillers and field views with dissimilar fillers produced equal rates of choosing, equal rates of correct identifications, and equal rates of false identifications.

The diagnostic value of the field view with similar fillers procedure (1.91) was compared to that of the field view with dissimilar fillers procedure (1.66). Analyses indicated that the difference in diagnosticity rates between the two procedures was not significant, $z=0.39, p=.697$, using a two-tailed test. The non-significant difference means that a suspect identification from a field view that contains similar fillers is no more indicative of that suspect's guilt than a suspect identification from a field view that contains dissimilar fillers.

Summary. The diagnosticity of field views with similar fillers, field views with dissimilar fillers, showups, lineups with similar fillers, and lineups with dissimilar fillers was $1.91,1.66,13.2,9.00$, and 3.11, respectively. Analyses revealed that the difference in diagnosticity rates between field views with similar fillers and showups was significant, $z=2.51, p=.012$, using a two-tailed test. The difference in diagnosticity between field views with dissimilar fillers and showups was also significant, $z=2.92, p=.004$, using a two-tailed test. These results indicate that a suspect identification from a showup has the potential to provide more additional information regarding the suspect's guilt, in comparison to the exploratory field view procedure (regardless of filler similarity).

Additionally, the difference in diagnosticity rates between field views with similar fillers and lineups with similar fillers was not significant, $z=1.61, p=.107$, but the difference in diagnosticity between field views with dissimilar fillers and lineups with similar fillers was significant, $z=2.01, p=.044$, using two-tailed tests. These results 
indicate that lineups also have the potential to offer more information regarding a suspect's guilt than the exploratory field view when the lineup contains similar fillers and the field view contains dissimilar fillers. However, if the field view contains similar fillers, it has the potential to provide an equal amount of information regarding the suspect's guilt, in comparison to a lineup with similar fillers.

\section{Information Gain Analyses}

Information gain analyses allow us to examine the amount we can update our beliefs regarding a suspect's guilt after that suspect is identified by a witness. Specifically, the amount of information gain is calculated as the difference between the suspect's probability of guilt prior to the identification (determined from incriminating and/or exonerating evidence), and the suspect's probability of guilt after the identification is made (Wells \& Olson, 2002). Information gain of a witness response from a specific identification procedure depends on two variables: The diagnosticity of that witness response from the given identification procedure (which is calculated from the data), and the prior (i.e., pre-lineup) probability of the suspect's guilt. Thus, information gain curves are graphed across the entire range of prior probabilities. The informational value of suspect identifications was calculated for all identification procedures (see Figure 1). Because inferential tests of differences in information gain across procedures are functionally equivalent to inferential tests of differences in diagnosticity (Wells \& Olson, 2002), which were already reported above, they are not repeated here.

Information gain associated with suspect identifications was highest for the showup procedure and peaked at approximately .57 , when the prior probability was .20 . Displaying a similar pattern, the maximum information gain for lineups with similar 
fillers peaked at approximately .50, when the prior probability was .25 . However, information gain was much lower for lineups with dissimilar fillers, peaking at approximately .28 , and at a prior probability of .35 . Information gain associated with suspect identifications was lowest for field views with dissimilar fillers, peaking at approximately .13 and field views with similar fillers, peaking at approximately .16, at prior probabilities of .45 and .40 , respectively.

Subsequent analyses were conducted to determine whether the information gain from a suspect identification was significantly different from 0 for each procedure. In other words, we wanted to examine whether a suspect identification from each of the procedures actually produced any information. Results indicated that information gain for each procedure was significantly different from 0 (field view with similar fillers $z=2.72$; $p=.006$; field view with dissimilar fillers $z=2.23 ; p=.026$; showup $z=6.34 ; p<.001$; lineup with similar fillers $z=5.02, p<.001$; lineup with dissimilar fillers $z=3.70$; $p<.001)$, using two-tailed tests.

\section{Additional Analyses}

In addition to the main analyses of the study, chi-square analyses were conducted to examine witnesses' expectations regarding the presence of the perpetrator in each procedure. Correlational analyses were performed to examine the relationship between confidence and identification accuracy.

Witnesses' expectations. Witnesses undergoing an exploratory field view procedure may have different expectations than witnesses undergoing a traditional identification procedure. For instance, in a lineup or showup, police always have a suspect. In an exploratory field view, police do not have a suspect. Perhaps knowing that 
there is not a suspect will allow the witness to rely more on his/her memory of the perpetrator and be less inclined to choose someone solely on the basis of their belief that the police have a suspect. Charman and Kavetski (in progress) provide one such study that supports the idea that witness expectations are particularly important during the showup procedure. However, research has yet to examine exploratory identification procedures and the effects that they may have on witnesses' expectations and identification accuracy.

We anticipate that if witnesses lower their expectations about the likelihood of the target's presence in an exploratory field view procedure, it would make them less inclined to choose when they are uncertain and would lead to fewer false identifications in the field view conditions than the lineup or showup conditions. It is important to note, that expectations were not manipulated in the current study and participants were not given any information regarding the procedure prior to participating in the identification task. As such, expectations were not expected to differ between procedures. However, if expectations did differ, the effects of such differences should be examined. Thus, witnesses' expectations were assessed.

In all conditions, participants were asked, "Before viewing the identification task, did you expect the perpetrator to be present?" and were given the options of, "Yes", "No", or "I had no expectations about the perpetrator's presence." Chi-square analyses were conducted to assess whether there were differences in the percentage of participants who expected the perpetrator to be present (i.e., responded "Yes") between procedures (i.e., field view, showup, lineup). Results indicated that participants expected the perpetrator to be present in the lineup more often than in the showup $(28.10 \%$ and 
$12.99 \%$ respectively, $p=.010$ ). There were no significant differences, however, in witnesses' expectations of the perpetrator's presence between the lineup and field view conditions $(20.26 \%, p=.109)$ or between the field view and showup conditions $(p=.174)$. Thus, results indicate that witnesses did not lower their expectations about the likelihood of the target's presence when undergoing the exploratory field view procedure. Further research is needed to examine factors that may influence identification accuracy in exploratory procedures, such as witness expectations.

Furthermore, recent research (Charman \& Kavetski, in progress) suggests that witnesses who undergo the showup procedure are particularly susceptible to suggestive influence, and are especially inclined to choose in target absent showups when they believe that police officers believe they have the perpetrator. Results of the analyses indicate that the showup procedure was not particularly suggestive in comparison to the lineup and field view procedures in the current study. In other words, the showups used in this study may be considered ideal showups (i.e., a showup procedure without any suggestive influence); showups in which witnesses believe the police have the perpetrator (which can occur for numerous reasons; Charman \& Kavetski, in progress) may result in worse showup performance.

Confidence-accuracy relationship. Correlational analyses were conducted to examine the relationship between participants' confidence in their decisions and accuracy of those decisions. Overall, there was a significant positive correlation between confidence and accuracy $(r=.25, n=383, p<.001)$, indicating that accurate responses tended to be made with somewhat higher confidence than inaccurate responses. Breaking down results by identification condition indicated that this relationship was also 
significant for field views with dissimilar fillers $(r=.47, n=78, p<.001)$, lineups with similar fillers $(r=.23, n=76, p=.042)$, and lineups with dissimilar fillers $(r=.26$, $n=77, p=.021)$. However, the correlation was non-significant for field views with similar fillers $(r=.18, n=75, p=.120)$ and showups $(r=.12, n=77, p=.290)$.

Choosers vs. Non-Choosers. The confidence-accuracy correlation was also examined for choosers and non-choosers separately. A chooser is considered any participant who made an identification, whether it was an identification of the suspect or a filler, while a non-chooser is anyone who does not make an identification (i.e., says that the perpetrator is not present in the identification procedure). Research suggests that the confidence-accuracy correlation is strongest for those that choose and that the relationship is a positive correlation (i.e., correct choosers are more confident than incorrect choosers; Sporer, Penrod, Read, \& Cutler, 1995). Results of the current study indicate that overall (i.e., collapsed across procedures), the relationship between confidence and accuracy was significant for choosers $(r=.28, n=189, p<.001)$. Specifically, the confidence-accuracy correlation was significant for field views with dissimilar fillers $(r=.40, n=42, p=.008)$, lineups with similar fillers $(r=.31, n=42$, $p=.049)$, and lineups with dissimilar fillers $(r=.33, n=38, p=.042)$ and nonsignificant for field views with similar fillers $(r=.17, n=40, p=.290)$ and showups ( $r=.15, n=27, p=.452$ ). Overall (i.e., collapsed across procedures), the relationship between confidence and accuracy was also significant for non-choosers $(r=.23, n=194$, $p=.001)$, but further examination of non-choosers revealed that the relationship was only significant for field views with dissimilar fillers $(r=.57, n=36, p<.001)$. 


\section{Discussion}

The results of Study 1 suggest that although identifications from the exploratory field view procedure produce some limited diagnostic information about the guilt of a suspect, the procedure tends to perform "worse" than the traditional procedures, as it results in inflated false identification rates. The fact that there is not an a priori suspect creates a major problem - anyone identified could come under suspicion. When an innocent person comes under suspicion, two issues arise: (1) there is the potential of convicting an innocent person - in this case, on the basis of a mistaken identification, and (2) police are not looking for the person who actually committed the crime, allowing the culprit to commit further offenses.

Because filler identifications in the target absent field view are considered false identifications, the field view resulted in significantly more false identifications than both the lineup and showup procedures. As expected, this effect was not moderated by filler similarity. Dissimilar fillers in the field view were not expected to increase overall choosing compared to similar fillers; instead, they were expected to result in an increased rate of choosing for one particular person in the procedure. On the other hand, similar fillers were expected to produce choices that were dispersed among all field view members. As such, dissimilar fillers and similar fillers should produce similar rates of false identifications. Results supported this prediction. Additionally, the diagnostic value associated with the exploratory field view procedure was limited, such that an identification of a guilty person was only slightly more likely (i.e., 1.78 times) than an identification of an innocent person. Overall, the results of the current study suggest that 
the detrimental effects of the exploratory field view procedure outweigh any potential benefits. 


\section{STUDY 2}

Although Study 1 revealed some disturbing findings regarding the exploratory field view procedure, Study 2 aimed to determine whether there are any conditions under which the field view might be considered an acceptable procedure. Given that Study 1 suggested the primary problem with field view identifications is that any person identified may be considered a suspect (which thus increased false identification rates), it is plausible that the field view may prove beneficial when police do in fact have a suspect in mind (and thus 'filler' identifications would be known errors, and not considered false identifications). Specifically, police may use a method similar to the exploratory field view after apprehending a suspect, by placing the suspect in a location and allowing the witness to walk around and determine whether the perpetrator is in that location. We will refer to this potential version of the field view as a confirmatory field view, as police would be confirming whether they should continue investigating the current suspect or pursue someone else.

To gain some insight on accuracy rates of this proposed procedure, we first reanalyzed some data from Study 1, by assuming that police used a confirmatory field view. Specifically, this re-analysis considers only identifications of the a priori innocent suspect as false identifications and treats other identifications (i.e., filler identifications) as known errors. Thus, we examined suspect identifications in the target absent conditions to determine how the confirmatory field view fares in comparison to the lineup and the showup procedures. 


\section{Re-evaluation of Study 1 Data: False Identifications}

Chi-square analyses revealed that when filler identifications in the field view condition were excluded from the analysis, several important findings emerged. First, the field view fared similarly to the traditional procedures. More specifically, when the field view contained similar fillers, it produced a rate of false identifications (5\%) that was equivalent to the rates produced by lineups with similar fillers $\left(6 \% ; \chi^{2}(1)=0.03\right.$, $p=.871)$ and showups $\left(5 \% ; \chi^{2}(1)=0.00, p=.959\right)$. Similarly, when the field view contained dissimilar fillers, it produced an equal rate of false identifications (24\%) to the lineup with dissimilar fillers $\left(19 \%, \chi^{2}(1)=0.39, p=.533\right)$. However, the field view with dissimilar fillers produced significantly more false identifications than the showup $\left(\chi^{2}(1)\right.$ $=5.65, p=.017)$.

Second, although the effect of filler similarity on false identifications was not significant in Study 1 for lineups or exploratory field views, dissimilar fillers resulted in significantly more false identifications than similar fillers in the confirmatory field view

procedure $\left(24 \%\right.$ and $5 \%$, respectively, $\left.\chi^{2}(1)=6.07, p=.014\right)$. This new finding supports previous research that suggests including dissimilar fillers in a lineup will result in more false identifications than if the lineup contained similar fillers (Fitzgerald et al., 2013).

Diagnosticity was also recalculated for the field view procedures. The diagnostic value of the field view with similar fillers procedure increased from 1.91 in the initial analysis of the exploratory procedure to 13.0 in the current analysis of the confirmatory procedure. The diagnostic value of field views with dissimilar fillers also increased slightly from 1.66 in the initial analysis to 2.63 in the current analysis. 
Subsequent analyses revealed that the difference in diagnosticity rates between the confirmatory field view with similar fillers and the showup (13.2) was not significant, $z=0.11, p=.912$, using a two-tailed test. This means that a suspect identification from a confirmatory field view with similar fillers and a suspect identification from a showup are equally indicative of that suspect's guilt. The difference in diagnosticity between the confirmatory field view with dissimilar fillers and the showup, however, was significant, $z=1.98, p=.048$, using a two-tailed test, meaning that a suspect identification from a showup is more indicative of that suspect's guilt than a suspect identification from a confirmatory field view with dissimilar fillers. Importantly, the diagnosticity rate of the exploratory field view (regardless of filler similarity) was significantly lower than that of showups, indicating that showups provide more information regarding a suspect's guilt when compared to the exploratory field view but equal information when compared to the confirmatory field view, when the confirmatory field view includes similar fillers.

Further, results indicated that the difference in diagnosticity between the field view with similar fillers and the lineup with similar fillers (9.00) was not significant, $z=1.43, p=.153$, using a two-tailed test, meaning that a suspect identification from a confirmatory field view with similar fillers is equally indicative of that suspect's guilt as a suspect identification from a lineup with similar fillers. This result was consistent with that of the exploratory field view procedure (i.e., the field view with similar fillers fares similarly to the lineup with similar fillers). However, previous results indicated that the lineup procedure may provide more information regarding a suspect's guilt than the exploratory field view procedure when the lineup has similar fillers and the field view has dissimilar fillers. The current analyses revealed that the confirmatory field view 
procedure has the potential to provide an equal amount of information regarding a suspect's guilt as the lineup with similar fillers procedure, even when the confirmatory field view includes dissimilar fillers, as the diagnosticity between the confirmatory field view with dissimilar fillers and lineup with similar fillers was not significant, $z=1.07$, $p=.285$, using a two-tailed test.

\section{The Confirmatory Field View Procedure}

The re-analyzed data from Study 1 support the idea that the confirmatory field view may be a practical identification procedure. That is, it does provide diagnostic information. Furthermore, it may be as good of a procedure as the traditional lineup and showup procedures, albeit under the provision that there is an a priori suspect and under the constraint that the fillers (i.e., people in the area) are similar to the suspect. In fact, we argue that the confirmatory field view may be a viable alternative to the showup procedure. Specifically, we argue that there are two aspects of the confirmatory field view that give it the potential to increase identification accuracy compared to the showup procedure. First, the confirmatory field view may be less suggestive than the showup because it contains fillers (assuming those fillers are similar to the suspect). Also, it is likely that people who are similar-looking to the perpetrator may be present in any given area. For instance, if the perpetrator to a crime is described as a Hispanic male in his midtwenties with dark hair, brown eyes, and an average build, and police decide to conduct a field view in a busy park near a college campus in south Florida, it is highly likely that there will be many Hispanic males in their twenties with dark hair, eyes, and an average build. It is also probable that police could quickly assess whether fillers in the area may be similar/dissimilar to the suspect before deciding to conduct the procedure. 
Second, we argue that the confirmatory field view may increase identification accuracy compared to the showup because the confirmatory field view can be administered by an officer who does not know the identity of the suspect, thus reducing the opportunity for administrator bias. This can never be done using the showup procedure.

\section{Administrator Bias}

Previous research has found that administrators' knowledge (of the suspect) can impact identification decisions made by witnesses (Phillips, McAuliff, Kovera, \& Cutler, 1999). An administrator who knows the identity of the suspect may give witnesses cues or encourage them to choose the suspect either intentionally or unintentionally. Greathouse and Kovera (2009) examined conditions under which administrator bias might be more or less influential by manipulating whether other potentially biasing factors (i.e., biased lineup instructions; simultaneous lineup presentation) were also present. In this study, participants served as either the administrator or the witness. Witnesses watched a video, completed a filler task, and completed an identification task. The administrators were trained on how to administer a lineup and were told that they would receive $\$ 20$ if their witness chose the suspect. Half of the administrators were trained to give biased instructions to the witnesses and half were trained to give unbiased instructions. Similarly, half were trained to administer a simultaneous lineup and half were trained to administer a sequential lineup. Importantly, half the administrators knew the identity of the suspect; the other half did not. Results indicated that the biasing influence of the non-blind procedures (i.e., the administrator knew the identity of the suspect) was greatest when other biasing factors were also present (specifically, biased 
instructions and a simultaneous lineup). They also found that non-blind administrators were more likely to give behavioral cues to witnesses urging them to choose the suspect. Finally, identifications made when the administrator did not know the identity of the suspect were more diagnostic of guilt than identifications made when the administrator knew the identity of the suspect.

More recently, Charman and Quiroz (in press) conducted a study examining whether similar effects would be found even when only unbiased instructions and sequential lineups were used. Participants came to the lab in pairs, where one participant was assigned to act as the witness and the other to act as the lineup administrator. Administrators were randomly assigned to be either blind or non-blind to the identity of the suspect. After witnesses viewed a mock crime video, the administrators read a set of standardized, unbiased instructions to the witnesses and administered the lineup task. Results of this study suggested that although correct identifications were relatively unaffected by administrator knowledge, both false identifications and witnesses' confidence in those false identifications significantly increased when the administrator knew the identity of the suspect.

Thus, the implementation of double-blind (i.e., neither the witness nor the administrator know the identity of the suspect) identification procedures is considered one of the most important recommendations in the eyewitness literature (National Research Council, 2014; Technical Working Group, 1999; Wells et al., 1998).

\section{Purpose}

In Study 1, it was necessary to use videotaped identification procedures to control for the similarity of fillers. However, the use of videotapes could lead witnesses to have 
different expectations than if the witnesses were allowed to walk around, as in a real field view. For instance, when participants are shown a videotaped identification task in Study 1, they may expect that the researcher placed/did not place the target somewhere in the video and be inclined to make their decision accordingly. In an ecologically valid procedure, participants may have different expectations, or no expectations, regarding the presence of the perpetrator and would thus make their decisions in another manner. Furthermore, witnesses may be offered more cues if given the opportunity to walk around and not be limited to what they are viewing or from what angle. Thus, it was important to maximize ecological validity in Study 2. To do so, Study 2 incorporated a live, staged incident and live field view and showup procedures. We also provided motivation to participants serving as administrators to obtain a suspect identification and to both administrator and witness participants to return a correct identification decision.

The primary goal of Study 2 was to determine whether a confirmatory field view, conducted in an ecologically valid manner, is a potential alternative to the showup procedure. This was assessed by comparing identification accuracy rates across the two procedures. The second goal of Study 2 was to examine whether identification accuracy varies as a function of blind (i.e., administrator does not know the identity of the suspect) vs. non-blind (i.e., administrator knows the identity of the suspect) administration. In Study 2, the lineup procedure was not examined for several reasons. First, having a lineup condition would necessarily confound certain variables in the study, as the lineup procedure would include photos of the suspect and fillers, whereas the field view and showup procedures would be conducted in-person. Additionally, the lineup condition was dropped for feasibility reasons. It would be possible to use several research assistants and 
conduct a lineup in person; however, this process would be very time-consuming.

Finally, and most importantly, a lineup condition was not included in Study 2 because it was unnecessary, considering the main purpose was to determine whether the confirmatory field view is a viable alternative to the showup.

\section{Hypotheses}

First, we argue that the confirmatory field view may offer a plausible alternative to the showup procedure, which is commonly criticized as being a suggestive procedure. Specifically, the confirmatory field view has the potential to maintain the major benefits of the showup (i.e., it does not take a long time to create/administer), while incorporating the major benefits of the lineup (i.e., contains fillers; can use double-blind administration). Thus, we expect that the confirmatory field view will produce comparable rates of correct identifications to the showup but will fare superior to the showup when the perpetrator is not present in the procedure by suppressing false identification rates.

More specifically, we expect that (1a) witnesses will choose more often from field views than from showups (due to the greater number of options), but that field views will (1b) produce equal correct identifications as showups. Because of the protection afforded innocent suspects in the confirmatory procedure via fillers, we expect that (1c) overall, field views will produce fewer false identifications than showups.

Furthermore, we predict that administration type (i.e., blind vs. non-blind) will affect suspect identifications. Specifically, based on past research (e.g., Charman \& Quiroz, in press; Greathouse \& Kovera, 2006), we expect that (2a) witnesses will choose equally often from a non-blind field view as from a blind field view. However, we expect 
that witnesses will choose the suspect more from a non-blind field view than from a blind field view, regardless of the perpetrator's presence in the location. In other words, we expect that (2b) non-blind field views will produce more correct identifications than blind field views, but will also (2c) produce more false identifications than blind field views.

We anticipate that the nature of the field view could introduce additional concerns when administered by someone who knows the identity of the suspect. For instance, in a showup or lineup, an administrator may introduce bias by eliciting verbal or nonverbal cues to the witness urging him/her to choose the suspect. However, these procedures are administered in a controlled setting that affords only limited opportunities to provide cues. In a field view, however, there are more ways an administrator may influence a witness's decision. For example, an administrator who knows the identity of the suspect may influence the witness's decision by leading the witness directly to the suspect or by walking past the suspect several times. Thus, this additional concern leads us to predict that (3a) witnesses will choose more often from non-blind field views than from showups. We also expect witnesses will choose the suspect, in particular, more often from non-blind field views than from showups, meaning that (3b) non-blind field views will result in more correct identifications than showups, and (3c) more false identifications than showups.

On the other hand, blind administration of the field view procedure should serve to protect an innocent suspect by eliminating administrator bias. An administrator who does not know the identity of the suspect, cannot intentionally, or unintentionally, encourage the witness to choose the suspect. A showup administrator cannot ever be blind to the identity of the suspect. Thus, we expect (4a) blind field views will result in 
more choices than in showups (again, because there are more options). However, because of the reduced chance for administrator bias in the blind field view condition, we expect blind field views to result in fewer suspect identifications than showups and we expect this difference in suspect identifications to be especially prominent in the target absent conditions. As such, we expect (4b) blind field views and showups will produce equal correct identifications, but we expect (4c) blind field views will result in fewer false identifications than showups.

\section{Method}

Participants. Participants included 416 undergraduate students. Half the participants $(n=208)$ participated as the witness and the other half participated as the administrator. The sample was primarily female $(68.5 \%)$ and Hispanic $(69.0 \% ; 13.8 \%$ African American; 10.4\% Caucasian; 1.7\% Asian; 5.1\% Other). The mean age of participants was 21.33 years old $(S D=3.59)$. Participants were recruited via the university's online recruitment system and through in-class sign-ups; up to eight people signed up for a given session. They were given either course credit or extra credit for their participation.

Design. After participating in a brief interaction with one of the targets, participants in Study 2 were randomly assigned to participate in a target present or target absent showup or target present or target absent field view that involved blind or nonblind administration. Thus, the study adhered to a 3 (Identification procedure: Blind field view vs. Non-blind field view vs. Showup) x 2 (Target presence: TP vs. TA) betweensubjects design. For this study, participants served as the administrators in the field view conditions, as using research assistants as administrators would not have allowed for 
blind administration. To maintain consistency across conditions, participants also administered the showup procedure. As in Study 1, the main dependent variables were choosing rates and the accuracy of the identification decisions. Unlike Study 1, however, Study 2 focused on maximizing ecological validity and did not use videotapes for any of the identification procedures.

Materials.

Recruitment of targets. Because Study 2 did not involve a mock crime, we will refer to "targets" instead of "perpetrators". Similar to Study 1, this study required two targets in order to have an a priori innocent suspect where each served as the other's target absent replacement in the target absent conditions. Targets were chosen on the basis that they matched the same overall description, were rated as similar to one another, and had overlapping availability, as they both had to be present during every data collection session. To recruit the targets, we contacted psychology undergraduate students by advertising a research assistant position via e-mail and by going to classes. The targets were required to sign up for a research course for the semester we conducted the study.

The overall descriptions were created by having five people view a 20 -second video clip of each potential target and subsequently provide a description of each. For each of the potential targets, the overall description included any characteristic that was listed by at least three of the five respondents. Similar to Study 1, the five respondents also provided similarity ratings for each pair of potential targets. Specifically, they viewed two video clips paired together and were asked, "How similar are the two girls in the videos?" on a scale from 1 (Extremely dissimilar) to 7 (Extremely similar). 
The two targets chosen were the pair who received the highest average similarity rating to each other (i.e., 5.00) and had overlapping availability for the semester (see Appendix $\mathrm{C}$ for a picture of the chosen targets). Their overall descriptions matched except for one characteristic. Target 1's description was Hispanic/White female with long, dark hair. Target 2's overall description was Hispanic/White female with long, dark, curly hair. It was obvious that all the potential targets differed on certain hair characteristics to varying degrees. Therefore, the targets were asked to wear their hair up for the study. We expected this instruction to the targets would help avoid obtaining identifications made solely on the basis of the target's hair.

Follow-up questionnaires. Follow-up questionnaires were created to examine participants' experience and beliefs about the identification procedures. We also questioned administrator participants about the instructions they provided to their witnesses and whether they believed they influenced their witnesses' decisions in any way. Witness participants were similarly questioned on whether they believed their administrators influenced their decisions and on how they made their decisions.

Procedure. When participants signed up, they were told that the study was designed to examine the association between personality traits and cognitive abilities. The purpose of this cover story was to ensure witness participants did not anticipate the interaction they were going to have during the study. After participants arrived in the conference room and signed consent forms, they were randomly assigned to participate as an administrator or as a witness. However, they were not informed of this condition. Subsequently, the administrator participants were escorted to a separate room so they 
would not have any knowledge of the witnesses' participation in the interaction and thus, did not know whether the suspect was guilty or innocent.

Participants in both rooms were given a packet that included a personality survey and several cognitively demanding tasks (e.g., Sudoku puzzles; math games), to accompany the cover story. All participants were asked to begin filling out the survey. One minute into the survey, we began the witness/target interactions. The interactions took place one at a time (i.e., one witness and the target) to maintain the assumption of independent observations in the data. Thus, the first witness participant was asked to step into the hall, where a research assistant was going to ask him/her some questions. Meanwhile, the targets were waiting in a third room in the hall and listening for the question that signaled them to begin the interaction. Upon hearing the cue question, the appropriate target - depending on the condition the participant was randomly assigned (i.e., interaction with Target 1 or 2 ) - stepped into the hall and performed the interaction memorized from a script (see Appendix D). The interaction involved the target asking the participant and research assistant if either of them were there to participate in a study, and subsequently providing the participant with information regarding a fictitious research study. The interaction lasted approximately 25 seconds. Upon the interaction's end, the target returned to the room, while the research assistant finished asking the participant questions and brought him/her back to the conference room to continue working on the packet. Then, the second witness was called into the hallway to begin the interaction process. This process continued until all witnesses participated in the interaction. After the interactions were complete, one of the research assistants called, for the second time, the first witness participant and asked him/her to step into the hall again. 
This time, the research assistant also went to the administrator room and called on the first administrator participant to step into the hall. She informed the pair of participants that the next part of the study required them to go to the library and that she would give them instructions when they arrived.

The identification procedures took place on the second floor of the university library. Participants were randomly assigned to participate in either a target present or target absent non-blind field view, blind field view, or showup. When they arrived at the library, the witness participant was asked to wait in a given location until the research assistant was ready for him/her. The administrator participant was directed to the location where the procedure would take place. The administrator was then informed of the previous interaction between the target and the other participant (i.e., their witness). Participants acting as the non-blind field view administrator and the showup administrator were led to the suspect and told that this person was the suspect, and that the suspect may or may not be the person their witness actually interacted with. They were told that it was their job to pretend they are the police officer in this situation and that they were going to administer the identification procedure and write down their witness's identification decision and confidence in his/her decision. They were given a clipboard and form to do so. Participants acting as the blind field view administrator were given the same instructions but were not informed of the identity of the suspect. In other words, the blind field view administrator knew that a suspect was in the location but only the non-blind administrators knew who the suspect was and where she was positioned in the location. All administrators were notified that they should not talk to anyone in the library but that if their witness identified the suspect, they would receive a $\$ 10$ gift card 
to Target. The reason for this incentive was to mirror a real world scenario, whereby police officers, regardless of their knowledge of the suspect's identity, have an incentive to obtain a suspect identification from the witness (i.e., it would reinforce their belief that they have correctly apprehended the target).

Next, the research assistant brought the witness to the administrator participant and provided the witness with instructions. The witness was first reminded of his/her previous interaction in the hallway and was then informed that he/she would have the task of making an identification decision. The witness was told to pretend the other participant is the police officer in this situation and that he/she would be administering the identification procedure and writing down the witness's decisions.

The pair of participants was informed that if the correct decision was made, they would both be given a shorter version of the follow-up questionnaire afterwards. The purpose of this incentive was again, to mirror a real-world scenario. In an actual case, police officers and witnesses presumably have incentive to obtain an accurate identification decision, as they should not want an innocent person to be mistakenly identified and wrongfully convicted. See Appendices E and F for full administrator and witness instructions.

The research assistant then allowed the pair of participants to begin the procedure. Participants in the field view conditions began walking around the section of the library to which they were confined and the participants in the showup condition began walking in the direction of the suspect. While the participants were working toward an identification decision, the research assistant remained far enough behind the participants to allow an interaction between the two but close enough to ensure the procedures were 
being performed correctly (e.g., that the administrators in the showup condition took the witness to the suspect and not someone else). The session ended when the pair of participants returned to the research assistant with an identification decision (i.e., "Made an identification" or "Did not make an identification") and the witness's confidence (on a scale from 0 (not at all confident) to 100 (extremely confident)) recorded on the form.

The research assistant confirmed that the witness's decision and confidence were accurately recorded and asked the witness to point out the person he/she identified if an identification was made. The purpose of this was to verify whether the identification was a suspect identification or a filler identification. The research assistant and participants then returned to a separate room of the lab to complete follow-up questionnaires (see Appendices $\mathrm{G}$ and $\mathrm{H}$ ). When one set of participants was finished with the procedure in the library, another set was cued to begin the process. This continued until all pairs of participants completed the identification procedure. After completing questionnaires, participants were debriefed, thanked for their participation, and dismissed. 


\section{RESULTS}

\section{Data Excluded from Analyses}

Before conducting the analyses, we excluded a total of 23 data points for various reasons. Fifteen participants were excluded because of participant mistakes. Specifically, some participants talked to the suspect during the procedure in the library $(n=3)$. Others were confused regarding the instructions $(n=5)$. For example, some participants later confirmed they were attempting to look for one of the other research assistants during the procedure instead of looking for the person with whom they interacted in the hallway. Additionally, during the showup procedure, participants were excluded if the administrator did not specifically point out the suspect and ask the witness if the suspect was the person he/she interacted with previously or if the witness was attempting to make a decision without getting a good view of the suspect's face $(n=7)$. An additional eight participants were excluded because of issues regarding the suspect's appearance (e.g., wore bright red nail polish that stood out to the participant; wore a jacket during the interaction, $n=3$ ) or due to various other research assistant mistakes $(n=5)$. After exclusions, data analyses included 185 data points (i.e., 370 participants).

\section{Comparison of the Confirmatory Field View to the Showup and Effects of}

\section{Administrator Knowledge}

Hypotheses 1-4 were tested using logistic regression analyses to compare choosing and accuracy rates for the confirmatory field view and showup procedures. Specifically, we compared overall field views (i.e., non-blind and blind) vs. showups, non-blind field views vs. blind field views, non-blind field views vs. showups, and blind field views vs. showups. For each comparison, choosing rates were first regressed onto 
procedure type, target presence, and the interaction of procedure type and target presence. Then, suspect identifications were regressed onto procedure type, target presence, and the interaction of the two variables. Chi-square analyses were conducted to further examine differences in correct and false identifications for each comparison (see Table 9 for all choosing and suspect identification rates and Tables 10-13 for logistic regression analyses). Similar to Study 1, diagnosticity of suspect identifications was also calculated and compared across identification procedures.

Field view vs. showup. Contrary to our expectations that witnesses would choose more often from field views than from showups (Hypothesis 1a), results from the logistic regression indicated that procedure type had no effect on choosing rates. In other words, participants chose as often from field views (30\%) as they did from showups $(33 \%), \beta=-$ 0.28 , Wald $\chi^{2}(1)=0.24, p=.623$.

The effect of procedure on suspect identifications was also not significant. Specifically, participants identified the suspect as often in field views as in showups ( $26 \%$ and $33 \%$, respectively; $\beta=0.69$, Wald, $\left.\chi^{2}(1)=1.30, p=.254\right)$. Therefore, consistent with our prediction (Hypothesis 1b), field views produced equal correct identifications as showups (41\% and 45\%, respectively; $\left.\chi^{2}(1)=0.15, p=.702\right)$.

However, inconsistent with our prediction that field views would produce fewer false identifications than showups (Hypothesis 1c), analyses revealed that field views and showups produced equal false identifications $\left(11 \%\right.$ and $20 \%$, respectively; $\chi^{2}(1)=1.34$, $p=.248)$. 
Overall, results indicate that the confirmatory field view and showup produce an equal rate of choosing, an equal rate of correct identifications, and an equal rate of false identifications.

The diagnostic value of the confirmatory field view (collapsed across non-blind and blind conditions) was 3.73 , meaning that a witness in this condition is 3.73 times more likely to identify the target when she was in the identification procedure than to identify an innocent suspect when the target was not present in the identification procedure. The diagnostic value of the showup procedure was 2.25. Subsequent analyses indicated that the diagnosticity rates of the two procedures were not significantly different, $z=0.47, p=.638$, using a two-tailed test. This means that a suspect identification obtained from a confirmatory field view and a suspect identification obtained from a showup are equally indicative of that suspect's guilt.

Non-blind field view vs. blind field view. Consistent with our prediction that witnesses would choose equally often from a non-blind field view as from a blind field view (Hypothesis 2a), results from the logistic regression indicated that procedure type (i.e., non-blind field view vs. blind field view) had no effect on choosing rates. Participants chose equally from the non-blind field view (34\%) as from the blind field view $(26 \%), \beta=-1.06$, Wald $\chi^{2}(1)=1.45, p=.228$.

However, contrary to our expectations, the effect of procedure type on suspect identifications was also not significant. Participants identified the suspect as often in the non-blind field view as in the blind field view (21\% and 33\%, respectively; $\beta=1.04$, Wald, $\left.\chi^{2}(1)=1.95, p=.163\right)$. Therefore, inconsistent with our prediction that non-blind field views would produce more correct identifications than blind field views (Hypothesis 
2b), non-blind field views and blind field views produced equal correct identifications $\left(45 \%\right.$ and $37 \%$, respectively; $\left.\chi^{2}(1)=0.15, p=.500\right)$.

Also inconsistent with our prediction that non-blind field views would produce more false identifications than blind field views (Hypothesis 2c), analyses revealed that non-blind field views and blind field views produced equal false identifications (16\% and $6 \%$, respectively; $\left.\chi^{2}(1)=1.56, p=.212\right)$.

Overall, results indicate that the non-blind field view and blind field view produce an equal rate of choosing, an equal rate of correct identifications, and an equal rate of false identifications.

Analyses comparing the diagnosticity rates of the two procedures ( 2.81 for the non-blind procedure and 6.17 for the blind procedure) indicated that the rates were not significantly different, $z=0.46, p=.646$, using a two-tailed test. Therefore, a suspect identification obtained from a field view where the administrator knows the identity of the suspect was equally indicative of that suspect's guilt as a suspect identification obtained from a field view that was conducted by a blind administrator. Importantly, this indicates that although our hypotheses were not supported, the confirmatory field view procedure was not biased by administrator knowledge. Perhaps witnesses undergoing the confirmatory field view procedure are less susceptible to suggestive influence than the traditional procedures.

Non-blind field view vs. showup. Because of our previous results suggesting that non-blind field views were equivalent to blind field views regarding choosing, correct identification, and false identification rates, it was not surprising to find the same pattern of results for non-blind views vs. showups. Specifically, inconsistent with our prediction 
that witnesses would choose more often from non-blind field views than from showups (Hypothesis 3a), results from the logistic regression indicated that procedure type had no effect on choosing rates. Participants chose equally from non-blind field views (34\%) and showups $(33 \%), \beta=-0.15$, Wald $\chi^{2}(1)=0.06, p=.806$.

The effect of procedure on suspect identifications was also not significant, such that participants identified the suspect as often in non-blind field views as in showups (31\% and $33 \%$, respectively; $\beta=0.26$, Wald, $\left.\chi^{2}(1)=0.15, p=.695\right)$. In other words, our prediction that non-blind field views would produce more correct identifications than showups (Hypothesis 3b), was not supported; in fact, the non-blind field view and the showup produced equal correct identifications $\left(45 \%\right.$ and $45 \%$, respectively; $\chi^{2}(1)=0.00$, $p=1.00)$.

Also inconsistent with our prediction that non-blind field views would produce more false identifications than showups (Hypothesis 3c), analyses indicated that nonblind field views and showups produced equal false identifications (16\% and 20\%, respectively; $\left.\chi^{2}(1)=0.16, p=.694\right)$.

Overall, results indicate that the non-blind field view and showup produce an equal rate of choosing, an equal rate of correct identifications, and an equal rate of false identifications.

Analyses were conducted to compare the diagnosticity rate of the non-blind field view procedure (2.81) to that of the showup procedure (2.25). Results indicated that the diagnosticity rates were not significantly different, $z=0.29, p=.772$, using a two-tailed test. In other words, a suspect identification was equally indicative of that suspect's guilt when obtained from a non-blind field view as when it was obtained from a showup. 
Blind field view vs. showup. Again inconsistent with our predictions, results did not support our hypothesis that witnesses would choose more often from blind field views than from showups (Hypothesis 4a). Instead, results from the logistic regression indicated that procedure type had no effect on choosing rates. Participants chose as often in showups (33\%) as they did in blind field views $(26 \%), \beta=-0.88$, Wald $\chi^{2}(1)=1.35$, $p=.245$.

The effect of procedure on suspect identifications was also non-significant, indicating that participants identified the suspect as often from blind field views as from showups $\left(21 \%\right.$ and $33 \%$, respectively; $\beta=1.32$, Wald, $\left.\chi^{2}(1)=2.36, p=.125\right)$. Therefore, consistent with our prediction (Hypothesis $4 \mathrm{~b}$ ), blind field views produced equal correct identifications as showups $\left(37 \%\right.$ and $45 \%$, respectively; $\left.\chi^{2}(1)=0.46, p=.500\right)$.

However, inconsistent with our prediction that blind field views would produce fewer false identifications than showups (Hypothesis 4c), analyses revealed that blind field views and showups produced equal false identifications (6\% and 20\%, respectively; $\left.\chi^{2}(1)=2.61, p=.107\right)$. Although the difference was not significant, the blind field view and showup procedures produced the greatest difference in false identifications rates out of any of the procedure comparisons.

Overall, results indicate that the blind field view and showup produce an equal rate of choosing, an equal rate of correct identifications, and an equal rate of false identifications.

The blind field view produced the highest diagnosticity rate of all the procedures (6.17). However, when compared to the procedure that resulted in the lowest diagnosticity of all the procedures, the showup (i.e., 2.25), the difference in diagnosticity 
rates was still not significant, $z=0.75, p=.453$, using a two-tailed test. This finding indicates that a suspect identification obtained from a blind field view and a suspect identification obtained from a showup are equally indicative of that suspect's guilt.

\section{Information Gain Analyses}

Similar to Study 1 , the informational value of suspect identifications was calculated for all identification procedures (i.e., non-blind field view, blind field view, showup; see Figure 2) across the entire range of prior probabilities of guilt. Again, because inferential tests of differences in information gain across procedures are functionally equivalent to inferential tests of differences in diagnosticity (Wells \& Olson, 2002), which were already reported above, they are not reported here.

Information gain associated with suspect identifications was highest for the blind field view procedure and peaked at approximately .43 , when the prior probability was .30. The maximum information gain for the non-blind field view peaked at approximately .25 , when the prior probability was .35 . Finally, information gain was lowest for showups, peaking at approximately .20 , and at a prior probability of .40 .

Subsequent analyses determined that the information gain from a suspect identification was significantly greater than 0 for each procedure (non-blind field view $z=2.55 ; p=.011 ;$ blind field view $z=3.20 ; p=.001 ;$ showup $z=2.12 ; p=.017)$, using two-tailed tests. In other words, a suspect identification from any of the procedures does provide additional information as to the guilt of the suspect.

\section{Additional Analyses}

Confidence-accuracy relationship. Correlational analyses were conducted to examine the relationship between participants' confidence in their decisions and accuracy 
of those decisions. Overall, there was a significant positive correlation between confidence and accuracy $(r=.15, n=185, p=.039)$, indicating that as confidence increased, accuracy increased as well. However, the correlation was not significant when examined by procedure type. Specifically, it was non-significant for non-blind field views $(r=.16, n=62, p=.212)$, blind field views $(r=.10, n=62, p=.447)$, and showups $(r=.18, n=61, p=.158)$.

Choosers vs. Non-choosers. Results indicate that overall (i.e., collapsed across procedures), the relationship between confidence and accuracy was significant for choosers $(r=.32, n=57, p=.016)$ but non-significant for non-choosers $(r=.09, n=128$, $p=.334)$. When examined by procedure type, results revealed that the confidenceaccuracy correlation was significant only for choosers in the non-blind field view condition, $(r=.44, n=21, p=.047)$, but not for choosers in the blind field view condition $(p=.719)$ or showup condition $(p=.153)$ or for non-choosers in the non-blind $(p=.856)$, blind $(p=.474)$, or showup $(p=.499)$ conditions.

\section{Discussion}

The results of Study 2 suggest that the confirmatory field view procedure tends to perform similarly to the showup procedure, as the two procedures resulted in equal correct and false identification rates. As such, our idea that the confirmatory field view could be used to improve upon the showup procedure was not supported. However, the results are still promising and indicate that the confirmatory field view could be a useful procedure. Specifically, there was no difference in accuracy when the field view was administered by an administrator who knew the identity of the suspect and an administrator who did not know the identity of the suspect. Perhaps this null finding 
indicates that the confirmatory field view procedure is less susceptible to administrator bias than the traditional procedures. Because of this, it may be beneficial to consider a field view in certain situations; for instance, when the administrator has a strong belief that the suspect is guilty and is thus, more likely to introduce bias into the procedure. Additionally, a confirmatory field view could be used to avoid later critique of the showup procedure. Because the confirmatory field view includes fillers and can be conducted using blind administration, it has the potential to avoid the main critique of the showup - that it is a suggestive procedure.

It is important to note, however, that filler similarity was not manipulated in Study 2. Because the re-evaluation of Study 1 data suggested that a field view with dissimilar fillers may produce more false identifications than a field view with similar fillers and a showup, filler similarity could have affected the outcome of Study 2. It is important to consider this factor, and others, in future research. Overall, the null findings of Study 2 are very meaningful. They suggest that the confirmatory field view may, in fact, operate at least as well as the showup. 


\section{OVERALL DISCUSSION}

The main purpose of the current project was to examine how the field view fares in comparison to the traditional eyewitness identification procedures. We currently know very little about the field view (e.g., how often it is used; how often they result in identifications; etc.), but we do know that it is a procedure used by law enforcement. Specifically, police will take a witness to a particular location and give that witness that task of determining whether the perpetrator is present in the location. Importantly, however, in these instances, police do not typically have a suspect during the procedure, deeming it an exploratory procedure. We anticipated the exploratory field view would be problematic for one main reason. That is, nobody in the area is known to be innocent. Because of this, an identification of anyone present, other than the actual perpetrator, is considered a false identification, and that person would come under suspicion as the suspect. Study 1 aimed to compare rates of identification accuracy between the exploratory field view, lineup, and showup and to examine whether filler similarity would moderate the effects of the field view procedure. Although results indicated that the three procedures fared similarly when the perpetrator was present in the location (i.e., they all produced equal correct identifications), the findings clearly demonstrated the potentially harmful consequences of exploratory procedures - specifically, the exploratory field view produced more false identifications than either the lineup or the showup. In fact, participants made an identification $36 \%$ of the time in the target absent field view condition, meaning that participants in the field view mistakenly identified someone more than one-third of the time. Furthermore, this effect was consistent, regardless of filler similarity. 
Experts in the field have recently recommended that researchers aim to develop alternative procedures to the lineup and showup traditionally used by law enforcement (Brewer \& Wells, 2011; Wells, 2014; Wells, Memon, \& Penrod, 2006). Wells (2014) argues that finding a solution to the problem of eyewitness misidentification should not focus on how to manipulate the current identification procedures (i.e., whether to show photos in a lineup simultaneously or sequentially) but should involve much more creative ways to increase identification accuracy. The NAS also acknowledged that one of the top priorities in the field should be to pinpoint specific system variables such as lineup procedures that can improve the accuracy of eyewitness identifications without introducing bias. It is imperative to develop an identification procedure that would be accepted by both researchers and law enforcement. To this end, the current study took an initial step with the examination of the confirmatory field view procedure.

In Study 2, we proposed that revising the field view to work as a confirmatory procedure (i.e., when police do have an a priori suspect) would be beneficial for two main reasons. First, it could solve the major issue of the exploratory procedure by including known innocent fillers. Second, it could provide a plausible alternative procedure to the showup. More specifically, we expected that a field view administered with an a priori suspect and by an administrator who does not know the identity of the suspect, would result in equal correct identifications but fewer false identifications in comparison to the showup procedure. In fact, a re-examination of Study 1 data provided initial support for the idea that the field view is a viable procedure under the constraints that there (1) is an a priori suspect and (2) are similar fillers in the area. Study 2 results supported this interpretation: The confirmatory field view, as opposed to the exploratory field view, 
resulted in identification accuracy equal to that of showups. In addition, Study 2 indicated that administrator knowledge of the suspect's identity did not affect identification accuracy in the confirmatory field view, suggesting that one potential problem with the confirmatory field view - that the administrator may know the identity of the suspect may not be as biasing as initially feared. In fact, both the non-blind and blind field views produced equal correct identifications and false identifications to the showup.

The null results regarding administrator knowledge on witness accuracy in Study 2 could be the result of a number of factors. For example, we informed administrator participants to try not to influence their witness's decision. Because they are students and administering identification procedures and evaluating evidence is not something in which they have experience, it is likely they attempted to strictly follow that instruction. On the other hand, it is possible that police officers, who are experienced in the administration of identification procedures, exhibit administrator knowledge effects. Unlike the student administrators in the current study, police officers do not have anyone "looking over their shoulder" to potentially inhibit any such administrator effects.

Furthermore, previous research suggests that the effects of administrator bias are strongest when other biasing factors are present. For instance, Greathouse and Kovera (2009) only found administrator bias when witnesses had an inclination to choose someone from the lineup, due to either biased lineup instructions or a simultaneous (cf. sequential) lineup presentation. In the current study, however, we attempted to limit any bias and participants were given unbiased instructions (and the field view could be considered effectively a sequential, not simultaneous, presentation). Although our findings did not support the idea that non-blind administration of the field view would 
introduce more bias (and thus, more false identifications) than even the showup, nor did it support the hypothesis that blind administration of the field view would introduce less bias (and fewer false identifications) than the showup, more research is needed before rejecting the idea.

\section{Practical Implications}

The current project significantly adds to the eyewitness literature as it is the first empirical study to examine the field view procedure. In fact, there is little to no published data regarding exploratory procedures. As such, the current findings have some important implications for law enforcement officers. Specifically, the lack of control over fillers in an exploratory procedure could be problematic for two reasons. First, the people in the area may all be extremely similar-looking to the perpetrator. In a traditional lineup, this would be a good thing, as similar fillers serve the purpose of protecting an innocent suspect. In an exploratory field view, however, if everyone in the area looks highly similar to the perpetrator, it could increase the witness's plausible response options and increase the likelihood of the witness making an incorrect choice. In other words, the high similarity of all the people in the area could increase the chance of the witness mistakenly identifying someone other than the perpetrator, when the perpetrator is present in that location. When this happens (i.e., when someone other than the perpetrator is identified in a target present procedure), the witness is not only providing exonerating evidence in favor of the guilty perpetrator and allowing a criminal to walk free, but is also identifying an innocent person. Because nobody in the exploratory field view procedure is known to be innocent, however, this mistaken identification should be considered a false identification, as that person would come under investigation. The 
results of Study 1 did not take "filler" identifications from target present field views into account when analyzing the overall false identification rate of exploratory field views. However, because the choosing rate from target present field views was $72 \%$ (similar fillers $=76 \%$; dissimilar fillers $=68 \%$ ), and the suspect identification rate from target present field views was only $64 \%$ (similar fillers $=65 \%$; dissimilar fillers $=63 \%$ ), we know that participants mistakenly identified an innocent person (while simultaneously incorrectly rejecting the guilty person) $8 \%($ similar fillers $=11 \%$; dissimilar fillers $=5 \%)$ of the time in target present exploratory field views. Thus, the main problem with the exploratory procedure - the inflated rate of false identifications (due to the lack of known innocent fillers) - was underestimated in the current analyses.

Second, if there are mostly people in the area who look nothing like the perpetrator, but one or two who do resemble the perpetrator, it could not only increase the likelihood of a false identification, but also increase the witness's confidence in that identification (Charman et al., 2011). However, results of Study 1 showed that the false identification rate for field views with similar fillers and field views with dissimilar fillers was equally high. Therefore, both circumstances are equally alarming. Overall, the current data suggest that exploratory procedures may result in more harm than good. Police should be cautious when beginning an investigation surrounding a person identified using the exploratory field view procedure, as research has shown that when a person comes under suspicion, subsequent evidence may be evaluated as more incriminating than it would have otherwise been evaluated (Charman, Kavetski, \& Hirn, in progress). 
Furthermore, although the confirmatory procedure may be a viable procedure when there are similar fillers in the area, police should first assess the situation to optimize identification accuracy. Specifically, they could quickly determine whether others in the area match the suspect on various characteristics. For instance, if the witness gave the description of the perpetrator as a Black male with braids and a goatee, police should not use this procedure if there is only one person in the area that matches the description. Instead, it may be more effective to first question the person in the area to determine whether he could be a potential suspect and then assess which is the best identification procedure to administer. For instance, it may be more time consuming to find a location that includes several fillers who look similar to the suspect. Additionally, even if an acceptable (i.e., on the basis of filler similarity) location is found, police still do not have control over the fillers. In other words, many of the fillers who look similar to the suspect may leave the location before or during the procedure. Because of these issues, it may not always be ideal to administer a confirmatory field view. Instead, a showup may be more useful in certain situations. On the other hand, a field view may be most beneficial in circumstances where the showup is likely to be more suggestive. For instance, if witnesses know that police have strong beliefs regarding the suspect's guilt, a confirmatory field view could be useful, as it contains fillers to protect an innocent suspect and it could be administered more quickly than a lineup. Additionally, a confirmatory field view could be conducted using blind administration to prevent later critique from triers of fact that the identification procedure was suggestive, or that the witness's decision was influenced by administrator bias. 
The findings of this project provide important implications for all triers of fact, including jurors, lawyers, and judges. It is essential for such people to consider not only that a witness made a suspect identification but to also consider the conditions under which the identification was made and during what procedure the identification was made.

\section{Limitations and Future Directions}

Several key limitations were present in the current studies. First, each procedure, particularly in Study 1, was not treated as a package. In other words, there were several fundamental issues with the procedures that did not mimic how the procedure is conducted in the real world. Instead, in an attempt to avoid many potential confounds, we aimed to maximize internal validity. For instance, in the real world, showups and field views are conducted in person. However, we used videotaped procedures. Furthermore, we did not use head and shoulder photos for our lineups, as are typically used in an actual lineup. Instead, we used images taken from the field view videos. After re-analyzing the data from Study 1, we found that confirmatory field views may fare similarly to lineups. However, we may find differences between the two procedures when treated as a package (i.e., lineups presented as a photo array vs. field views presented in person). Additionally, all the procedures were conducted after a 15 minute delay. In the real world, however, it is likely that the delay between the time of the crime and the identification procedure will be longer than 15 minutes, but especially for the lineup procedure. Although some recent research suggests that delay may not affect identification accuracy when examining lineups vs. showups (i.e., Wetmore et al., 2015), it is clear that memory weakens over time and as such, decreased accuracy is certain at some length of delay; more research is 
needed to determine at what length of delay it is more efficient to use one procedure over another procedure.

Another potential limitation is that neither in Study 1 nor Study 2 did we manipulate witnesses' expectations. We predict that witnesses' expectations regarding the presence of the perpetrator (before beginning participation in the identification procedure) may (1) be influenced by the type of procedure the witness is undergoing, but also (2) potentially moderate the effects of the field view on choosing rates. Recent research suggests that witnesses undergoing the showup procedure are particularly susceptible to suggestive influences (Charman \& Kavetski, in progress). This is especially problematic when considering that a witness who is administered a showup procedure is likely to have expectations that police have some information against this particular person - otherwise, why would they be administering the showup procedure? On the other hand, exploratory field views do not involve an a priori suspect and having such knowledge could potentially alter the likelihood of a witness guessing (i.e., it could reduce choosing when the witness is unsure). As such, future research should examine whether the effects of this manipulation could result in more promising results of the exploratory field view procedure.

Another limitation of the current project emerged in Study 2. We were not able to measure behavioral or verbal cues of administrator influence/bias. Because we were more interested in the effects of blind vs. non-blind administration on identification accuracy and not in the effects of administrator knowledge of the suspect on administrator behavior, we were not able to measure the latter. We attempted to record audio clips of the procedure when the administrator and witness participants were completing the 
identification task, by inserting a usb recording device into the pencil bag attached to the clipboard and decision form. However, because of the movement and background noise in the library, many of the recordings were too muffled to discern. As such, we can only rely on self-report data to determine administrator influence. Future research should aim to more thoroughly examine the nature of administrator-witness interactions while undergoing a field view procedure.

In addition to addressing the major limitations of the current project, future directions should first attempt to gain understanding regarding the administration of the field view in the real world. Often in research, we attempt to determine ways of manipulating procedures to increase correct identifications and decrease false identifications, without knowing the specifics of law enforcement procedure. If we first gain a better understanding of the procedure itself, how police conduct the procedure, and how much weight police place on varying witness responses within each procedure, it will better serve us in generating better study ideas. Currently, one study (Kavetski \& Charman, in progress) aims to address some of these issues. Specifically, we will determine whether investigators are appropriately sensitive to the diagnostic value of eyewitness evidence (e.g., likelihood that a suspect identification is indicative of that suspect's guilt), particularly when conducting the field view procedure. Previous research has examined this topic and generally has found that although investigators are sensitive to the fact that a suspect identification contains diagnostic value as to the guilt of a suspect, they also tend to overestimate its value (Boyce, Lindsay, \& Brimacombe, 2008; Dahl, Brimacombe, \& Lindsay, 2009; Dahl, Lindsay, \& Brimacombe, 2006). However, most of the studies examining this topic have used either student investigators or forensic 
investigators and have never examined the issue in regards to the field view procedure. In the study currently underway, police will be provided with information of a case and evidence against a suspect and asked to provide an initial likelihood rating that the suspect is guilty based on the evidence they were provided. Then, they will be informed that a witness either made an identification of the suspect, made an identification of a filler, or did not make an identification and will be asked to provide a second rating regarding the suspect's likelihood of guilt. By calculating the difference between the two estimates of guilt ratings, we will ascertain the perceived diagnostic value of the witness's identification responses, which can then be compared to the actual diagnostic value of the identification procedure. Additionally, the study will include a survey portion to obtain further information from police officers on topics including how they document the procedure, the steps that are taken when an identification is made, etc.

\section{Conclusion}

The current project provides the first empirical test of the field view procedure and examined two potentially moderating variables of the procedure. Altogether, the results suggest that an exploratory procedure can be very harmful to an innocent person who happens to be in the wrong place at the wrong time. Real world exoneration cases such as that of Ayers and Boquete illustrate the potentially damaging effects of the exploratory field view. However, it is unreasonable to believe that law enforcement will stop using exploratory procedures such as the field view, as their implementation can have obvious benefits (e.g., quickly determining whether the perpetrator is in a location). Therefore, it is imperative to further explore this procedure to determine whether there are any conditions under which it may be acceptable. 
On the other hand, the initial data on the proposed confirmatory procedure show promising results. That is, the confirmatory field view can be at least as good as a showup or a lineup. More specifically, findings indicate that one of the two potentially moderating variables tested was important (i.e., filler similarity), but the other was not (i.e., administrator knowledge of the suspect's identity). The current project suggests that a confirmatory field view may be acceptable when there are others in the area who look similar to the suspect. Results also suggest that witnesses undergoing the confirmatory field view procedure may be less susceptible to suggestive influence than the showup procedure, as participants undergoing the non-blind field view procedure performed equally to those undergoing the blind field view procedure. As such, it is possible that future research could reflect this advantage of the field view procedure over the showup procedure in terms of identification accuracy. One thing is certain: Much more research is needed on methods of increasing identification accuracy outside of the traditional identification procedures and on exploratory procedures. 


\section{REFERENCES}

Agricola, B. H. (2009). The psychology of pretrial identification procedures: The showup is showing out and undermining the criminal justice system. Law \& Psychology Review, 33, 125-137.

Behrman, B. W., \& Davey, S. L. (2001). Eyewitness identification in actual criminal cases: An archival analysis. Law and Human Behavior, 25, 475-491.

Boyce, M. A., Lindsay, S. D., \& Brimacombe, E. A. (2008). Investigating Investigators: Examining the impact of eyewitness identification evidence on studentinvestigators. Law and Human Behavior, 32, 439-453. doi: 10.1007/s10979-0079125-5

Brewer, N. \& Wells, G. L. (2011). Eyewitness identification. Current Directions in Psychological Science, 20, 24-27. doi: 10.1177/0963721410389169

Charman, S. D. \& Quiroz, V. (in press). Blind lineup administration reduces both false identifications and confidence in those false identifications.

Charman, S., \& Wells, G. L. (2007). Applied lineup theory. The handbook of eyewitness psychology, Vol II: Memory for people. (pp. 219-254) Lawrence Erlbaum Associates Publishers, Mahwah, NJ. Retrieved from http://ezproxy.fiu.edu/login?url=http://search.proquest.com/docview/621689051? accountid $=10901$

Charman, S. D., Wells, G. L., \& Joy, S. W. (2011). The dud effect: Adding highly dissimilar fillers increases confidence in lineup identifications. Law and Human Behavior, 35, 479-500. doi:http://dx.doi.org/10.1007/s10979-010-9261-1

Dahl, L. C., Brimacombe, E. A., \& Lindsay, S. D. (2009). Investigating investigators: How presentation order influences participant-investigators' interpretations of eyewitness identification and alibi evidence. Law and Human Behavior, 33, 368380. doi: 10.1007/s10979-008-9159-y

Dahl, L. C., Lindsay, S. D., \& Brimacombe, E. A. (2006). Investigating investigators: Examining witnesses' influence on investigators. Law and Human Behavior, 30, 707-732. doi: 10.1007/s10979-006-9012-5

Dwyer, J. (2007, February 11). Fugitive. The New York Times Magazine. Retrieved from http://www.nytimes.com 
Dysart, J. E., \& Lindsay, R. C. L. (2007). Show-up identifications: Suggestive technique or reliable method? The handbook of eyewitness psychology, Vol II: Memory for people. (pp. 137-153) Lawrence Erlbaum Associates Publishers, Mahwah, NJ. Retrieved from http://ezproxy.fiu.edu/login?url=http://search.proquest.com/docview/621688981? accountid=10901

Ebbinghaus, H. (1885). Memory: A contribution to experimental psychology. New York: Dover.

Fitzgerald, R. J., Price, H. L., Oriet, C., \& Charman, S. D. (2013). The effect of suspectfiller similarity on eyewitness identification decisions: A meta-analysis. Psychology, Public Policy, and Law, 1-14.

Garrett, B. L. (2011). Convicting the innocent. Where criminal prosecutions go wrong. Cambridge, MA: Harvard University Press.

Greathouse, S. M. \& Kovera, M. B. (2009). Instruction bias and lineup presentation moderate the effects of administrator knowledge on eyewitness identification. Law and Human Behavior, 33, 70-82. doi: 10.1007/s10979-008-9136-X

Luus, C. A. E. \& Wells, G. L. (1991). Eyewitness identification and the selection of distracters for lineups. Law and Human Behavior, 15, 43-57.

National Research Council (2014). Identifying the culprit: Assessing eyewitness identification. National Academies Press, Washington, DC. Retrieved from http://ezproxy.fiu.edu/login?url=http://search.proquest.com/docview/1655769326 ?accountid=10901

Orlando Boquete. (2016). In The national registry of exonerations: A project of the University of Michigan Law School. Retrieved from https://www.law.umich.edu

O'Rourke, T. (2016, February 25). How a wrongfully convicted man's case changed Cincinnati's Justice System. WCPO9 Cincinnati. Retrieved from http://www.wcpo.com

Phillips, M. R., McAuliff, B. D., Kovera, M. B., \& Cutler, B. L. (1999). Double-blind photo array administration as a safeguard against investigator bias. Journal of Applied Psychology, 84, 940-951.

Sauer, J. D., Brewer, N., \& Weber, N. (2008). Multiple confidence estimates as indices of eyewitness memory. Journal of Experimental Psychology: General, 137, 528547. doi:10.1037/a0012712 
Steblay, N., Dysart, J., Fulero, S., \& Lindsay, R. C. L. (2003). Eyewitness accuracy rates in police showup and lineup presentations: A meta-analytic comparison. Law and Human Behavior, 27(5), 523-540. doi:http://dx.doi.org/10.1023/A:1025438223608

Sporer, S. L., Penrod, S., Read, D., \& Cutler, B. (1995). Choosing, confidence, and accuracy: A meta-analysis of the confidence-accuracy relation in eyewitness identification studies. Psychological Bulletin, 118, 315-327.

Technical Working Group for Eyewitness Evidence. (1999). Eyewitness evidence: A guide for law enforcement. Washington, DC: United States Department of Justice, Office of Justice Programs.

Tunnicliff, J. \& Clark, S. E. (2000). Selecting foils for identification lineups: Matching suspects or descriptions? Law and Human Behavior, 24, 2000.

Wells, G. L. (1978). Applied eyewitness-testimony research: System variables and estimator variables. Journal of Personality and Social Psychology, 36, 15461557.

Wells, G. L. (2014). Eyewitness identification: Probative value, criterion shifts, and policy regarding the sequential lineup. Current Directions in Psychological Science, 23, 11-16. doi: 10.1177/0963721413504781

Wells, G. L., Ferguson, T. J., \& Lindsay, R. C. L. (1981). The tractability of eyewitness confidence and its implications for triers of fact. Journal of Applied Psychology, 66, 688-696.

Wells, G. L. \& Lindsay, R. C. L. (1980). On estimating the diagnosticity of eyewitness nonidentifications. Psychological Bulletin, 88, 776-784.

Wells, G. L., Memon, A., \& Penrod, S. D. (2006). Eyewitness evidence: Improving its probative value. Psychological Science in the Public Interest, 7, 45-75.

Wells, G. L. \& Olson, E. A. (2002). Eyewitness identification: Information gain from incriminating and exonerating behaviors. Journal of Experimental Psychology: Applied, 8, 155-167. doi:10.1037//1076-898X.8.3.155

Wells, G. L. \& Quinlivan, D. S. (2009). Suggestive eyewitness identification procedures and the Supreme Court's reliability test in light of eyewitness science: 30 years later. Law and Human Behavior, 33(1), 1-24.

Wells, G. L., Rydel, S. M., \& Seelau, E. P. (1993). On the selection of distractors for eyewitness lineups. Journal of Applied Psychology, 78, 835-844. 
Wells, G. L., Small, M., Penrod, S., Malpass, R. S., Fulero, S. M., \& Brimacombe, A. E. (1998). Eyewitness identification procedures: Recommendations for lineups and photospreads. Law and Human Behavior, 22, 603-647.

Wells, G. L., Yang, Y., \& Smalarz, L. (2015). Eyewitness identification: Bayesian information gain, base-rate effect equivalency curves, and reasonable suspicion. Law and Human Behavior, 29, 99-122.

Wetmore, S. A., Neuschatz, J. S., Gronlund, S. D., Wooten, A., Goodsell, C. A., \& Carlson, C. A. (2015). Effect of retention interval on showup and lineup performance. Journal of Applied Research in Memory and Cognition, 4(1), 8-14. doi:http://dx.doi.org/10.1016/j.jarmac.2014.07.003

WWw.innocenceproject.org

Zimmermann D. M., Austin, J. A. \& Kovera, M. B. (2012). Suggestive eyewitness identification procedures. In B. L. Cutler (Ed.), Conviction of the innocent. Lessons from psychological research (pp. 125-148). Washington, DC: American Psychological Association. 
APPENDICES 


\section{APPENDIX A}

Study 1 Identification Task Instructions

\section{All participants will receive the following instructions:}

"In the video you previously viewed, the girl was on the $5^{\text {th }}$ floor of the Green library. She is suspected of stealing the debit card of another student who left her purse at the cubicle while she was returning a book to the shelf. When the student realized her debit card had been stolen, she reported it to campus police. As a witness to this crime, you are going to be asked to make an identification decision and will then be asked some other questions. You may now click on the "next" arrows to move on to the identification task, and I will give you additional instructions."

The screen will display an X, Y, or Z. Read the corresponding instructions to participants.

\section{(X) Exploratory field view:}

Approximately 15 minutes after the incident, videos were taken of some of the students present in the library. You are about to view a video of students who were on the second floor of the library. Your job is to let us know if the person from the previous video is present in this video. Before you begin, I want to let you know that you may pause the video and may also rewind and replay the video as many times as you like until you have made a decision. The person you saw in the previous video may or may not be present in the video you are about to see. So when you are ready, you may move to the next screen, begin watching the video, and please let me know when you've decided whether the person is or is not present in this video.

\section{(Y) Showup:}

Approximately 15 minutes after the incident, video clips were taken of some of the students present in the library. You are about to view a video clip of a student who was on the second floor of the library. Your job is to let us know if the 
person from the previous video is the same person in this clip. Before you begin, I want to let you know that you may pause the video clip and may also rewind and replay the video clip as many times as you like until you have made a decision. The person you saw in the previous video may or may not be present in the clip you are about to see. So when you are ready, you may move to the next screen, begin watching the clip, and please let me know when you've decided whether the person is or is not present in this clip.

\section{(Z) Lineup:}

Approximately 15 minutes after the incident, pictures were taken of some of the students present in the library. You are about to view several photos of students who were on the second floor of the library. Your job is to let us know if the person from the previous video is present in the photos. Before you begin, I want to let you know that you may take as much time as you like until you have made a decision. The person you saw in the previous video may or may not be present in the photos you are about to see. So when you are ready, you may move to the next screen, begin viewing the photos, and please let me know when you've decided whether the person is or is not present in these photos. 


\section{APPENDIX B}

Study 1 Follow-up Questionnaires

\section{Instructions: Please answer the following questions using the given scale. Please read all the questions carefully.}

How good of a view did you get of the girl in the crime video?

$\begin{array}{ccccccc}1 & 2 & 3 & 4 & 5 & 6 & \begin{array}{c}7 \\ \text { Very good }\end{array} \\ \text { Very poor } & & & & & & \end{array}$

How long would you estimate the girl's face was in view during the crime video?

$\begin{array}{ccccccc}1 & 2 & 3 & 4 & 5 & 6 & 7 \\ \text { Very little time } & & & & & \text { Quite a bit of time }\end{array}$

How well were you able to make out specific features of the girl's face from the crime video?

$\begin{array}{ccccccc}1 & 2 & 3 & 4 & 5 & 6 & 7 \\ \text { Not at all } & & & & & & \text { Very well }\end{array}$

How far away was the girl in the crime video?

$\begin{array}{ccccccc}1 & 2 & 3 & 4 & 5 & 6 & 7 \\ \text { Notfar } & & & & & & \text { Veryfar }\end{array}$

How much attention were you paying to the girl's face while viewing the crime video?

$\begin{array}{ccccccc}1 & 2 & 3 & 4 & 5 & 6 & 7 \\ \text { None } & & & & & & \text { My full attention }\end{array}$

What were you paying the most attention to while viewing the crime video (i.e., the girl's face, her clothes, etc.)? 
To what extent do you feel that you had a good basis (enough information) to make an identification decision?

$$
\begin{array}{ccccccc}
1 & 2 & 3 & 4 & 5 & 6 & 7 \\
\text { No basis at all } & & & & & & \text { A very good basis }
\end{array}
$$

How easy or difficult was it for you to decide whether the girl from the crime video was present or absent in the identification task?

$\begin{array}{cccccccc}1 & 2 & 3 & 4 & 5 & 6 & 7 \\ \text { Extremely easy } & & & & & & \text { Extremely difficult }\end{array}$

After you were first shown the identification task, how long do you estimate it took you to make a decision?

$$
\begin{array}{ccccccccc}
1 & 2 & 3 & 4 & 5 & 6 & 7 \\
\text { I needed almost no time at all } & & & & & & \text { I needed a lot of time }
\end{array}
$$

On the basis of your memory of the girl in the crime video, how willing would you be to testify in court to the decision you made in the identification task?

$\begin{array}{ccccccc}1 & 2 & 3 & 4 & 5 & 6 & 7 \\ \text { Not at all willing } & & & & & & \text { Extremely willing }\end{array}$

Generally, how good is your recognition memory for strangers you have encountered on only one prior occasion?

$\begin{array}{ccccccc}1 & 2 & 3 & 4 & 5 & 6 & 7 \\ \text { Very poor } & & & & & & \text { Very good }\end{array}$

Q36 How clear is the image you have in your memory of the person you saw in the crime video?

$\begin{array}{lllllll}1 & 2 & 3 & 4 & 5 & 6 & 7 \\ \text { Not at all clear } & & & & & & \text { Very clear }\end{array}$




\section{Demographic Questions}

What is your age (in years)?

What is your gender?

Male Female Prefer not to answer

Please select what you feel best reflects your ethnic/racial identity.

Caucasian African American Hispanic Asian Other:

What is the highest level of education you have completed?

Highschool

Freshman year in college

Sophomore year in college

Junior year in college

Senior year in college

Graduate school

Other

Instructions: The following questions are very important. Please answer all to the best of your ability.

Before viewing the identification task, did you expect the perpetrator to be present?

Yes

No

I had no expectations about the perpetrator's presence

Was your decision influenced by the clothing the person/people in the identification task was/were wearing?

Yes

No

If yes, please explain. 
If you are reading this, please select Agree.

\begin{tabular}{|c|c|c|c|c|c|c|}
\hline $\begin{array}{l}\text { Strongly } \\
\text { Disagree }\end{array}$ & Disagree & $\begin{array}{l}\text { Somewhat } \\
\text { Disagree }\end{array}$ & $\begin{array}{c}\text { Neither } \\
\text { Disagree } \\
\text { nor Agree }\end{array}$ & $\begin{array}{c}\text { Somewhat } \\
\text { Agree }\end{array}$ & Agree & $\begin{array}{c}\text { Strongly } \\
\text { Agree }\end{array}$ \\
\hline
\end{tabular}

Do you know the person or any of the people you saw in photos or videos while participating in this study? Even if you recognize someone but do not know her name, please select "Yes".

Yes

No

If yes, please explain.

Please provide any other comments you may have regarding how you made a decision in the identification task.

\section{Additional Open-Ended Questions for participants in the Field View Conditions:}

Do you think the video you saw during the identification task helped you make your decision? If yes, please explain.

Do you think the video you saw during the identification task made it difficult to make a decision? If yes, please explain.

Do you think it would have been easier to make a decision if you saw head-shots of the six girls' faces (i.e., no clothes, body, etc.) instead of the video? Why or why not?

Do you think people who see the video during the identification task are MORE or LESS likely to make an accurate decision than someone who views only head-shots of the six girls? Please explain.

Do you think police officers should/could use a similar procedure (i.e., walking around with a witness) in the real world during an identification task? Please explain. 
APPENDIX C

Study 2 Targets

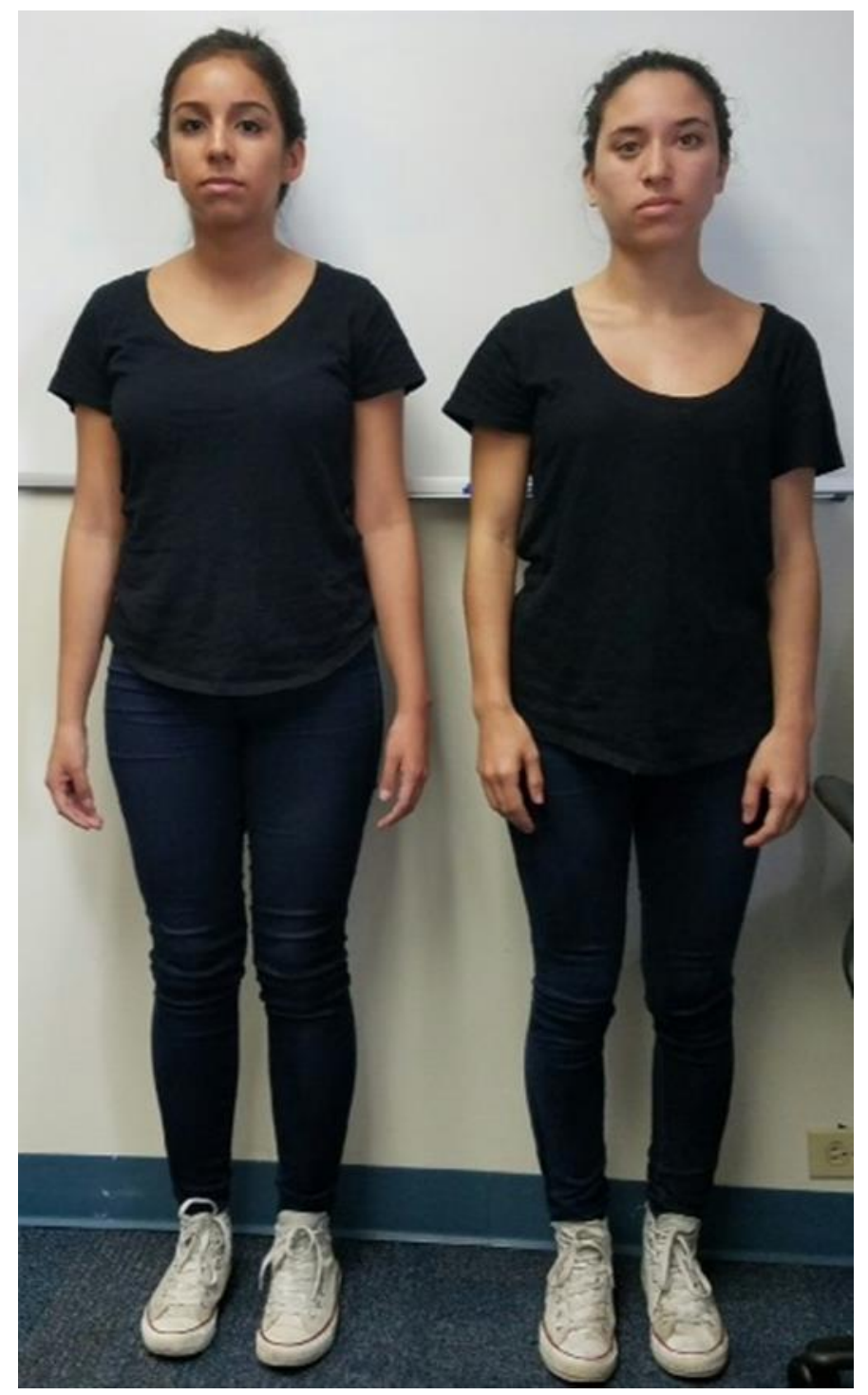




\section{APPENDIX D}

\section{Study 2 Interaction Script}

While RA1 is asking the participant questions, the appropriate actor will be listening, will wait for the "cue" question (Date of expected graduation), and will step out of DM 219A and say:

- "Excuse me, are either of you here for the Developmental study?" (wait for response)

○ RA1 will immediately say, "No, we're not".

- The participant should say "no", but if not, that is okay. RA1's response can serve as an answer for both of them.

- "Well, are either of you taking any psychology classes this semester?" (wait for response)

○ RA1 will say no and witness should say yes

- If witness also says "no", then continue with the script anyways. It will still work out fine the way it is rewritten.

- “Okay, one second..." (step back inside, grab the flyer, and step back outside)

○ Do this quickly - Do not shut the door and spend time inside the room. Just barely step back, reach around the door, and grab the paper off the desk.

Step to the witness and hand him/her the paper while saying:

- "Well if you or any of your friends need any sona credits, we're conducting a study called 'Memory Development'." (point to the name of the study on the paper)

- "It's on sona and we have sign-ups Monday through Friday." (point to times on the paper)

- "And it's worth one credit." (point to credits on paper) 
- 'Sorry, I don't have extra copies of this paper to give you (taking the paper back from the participant), but if you're interested, feel free to sign up, or tell your friends about the study."

RA1 will say:

- "Okay, thank you."

○ This should help end the conversation and make it a little less awkward if the participant doesn't say anything. 


\section{APPENDIX E}

Study 2 Administrator Instructions: Non-blind Field View Condition

"Now, I am about to give you some instructions for your next task. Once I finish reading you the instructions, you are going to have to follow all the instructions. So it is very important you pay attention to what I am about to explain and if at any time you do not understand me or need me to repeat something, please let me know. Okay?...

...Earlier, the participant that I told to wait at the escalator was called into the hallway to answer some questions. During that time, he/she had a brief interaction with someone. Imagine that the person he/she interacted with committed a crime, and the participant at the escalator is the witness to that crime. Now YOUR job is to pretend you are the police officer in this situation and you will be administering an identification procedure to your witness...

...Imagine, as a police officer, you have a suspect for this crime. We have placed a suspect in this section of the library (pointing towards section). The suspect we have placed here may or may not be the person the witness interacted with previously. We want to know whether the witness will identify this suspect - (walk the administrator to the actor, stopping an appropriate distance away) - That is our suspect (point to the actor - actor should wave). Your job is to walk the witness around this area of the library, anywhere from this bookshelf (pointing) to that wall (still pointing), and see if the witness identifies someone as the person he/she interacted with previously. You will be responsible for instructing the witness on this procedure. You will also be responsible for recording the decisions that your witness makes."

Hand participant the clipboard and say:

'Your witness may either make an identification or say, 'not there'. In other words, your witness may say that someone in this area is the person she interacted with previously or 
that the person she interacted with previously is not in this area. You'll notice the decision options are 'Made identification' and 'Did not make identification' (point to this on the form). Based on what the witness tells you, you will have to circle one of these decisions. Also, if your witness makes an identification, you will have to write down a brief description of the person your witness identified (point to this on the form)...

...There is one more thing I need to explain - The suspect we have placed in the library may or may not be the person your witness interacted with previously. That is his/her decision to make. However, IF your witness identifies this suspect, meaning he/she says that our suspect is the person he/she interacted with previously, YOU will get a $\$ 10$ gift card to Target. However, there are a few rules: First, you may talk to the witness but neither of you should talk to, or interact with, anyone in the library. Second, you should avoid influencing the witness's decision. For instance, you can't tell the witness he/she has to make an identification. And finally, it is important that you do NOT discuss the gift card with the witness, because he/she will not get one; only you will get one if he/she identifies this suspect. Do you understand these rules?" (wait for response)

"Okay, and after your witness has made a decision, you will need to ask your witness how confident he/she is in his/her decision, out of a percentage from $0-100 \%$ (point to the question on the form). You will record that percentage on the form as well... Now wait here and let me go get the other participant." 


\section{APPENDIX E}

Study 2 Administrator Instructions: Blind Field View Condition

"Now, I am about to give you some instructions for your next task. Once I finish reading you the instructions, you are going to have to follow all the instructions. So it is very important you pay attention to what I am about to explain and if at any time you do not understand me or need me to repeat something, please let me know. Okay?...

...Earlier, the participant that I told to wait at the escalator was called into the hallway to answer some questions. During that time, he/she had a brief interaction with someone. Imagine that the person he/she interacted with committed a crime, and the participant at the escalator is the witness to that crime. Now YOUR job is to pretend you are the police officer in this situation and you will be administering an identification procedure to your witness...

...Imagine, as a police officer, you have a suspect for this crime. We have placed a suspect in this section of the library (pointing towards section). The suspect we have placed here may or may not be the person the witness interacted with previously. We want to know whether the witness will identify this suspect. Your job is to walk the witness around this area of the library, anywhere from this bookshelf (pointing) to that wall (still pointing), and see if the witness identifies someone as the person he/she interacted with previously. You will be responsible for instructing the witness on this procedure. You will also be responsible for recording the decisions that your witness makes."

Hand participant the clipboard and say:

"Your witness may either make an identification or say, 'not there'. In other words, your witness may say that someone in this area is the person she interacted with previously or that the person she interacted with previously is not in this area. You'll notice the 
decision options are 'Made identification' and 'Did not make identification' (point to this on the form). Based on what the witness tells you, you will have to circle one of these decisions. Also, if your witness makes an identification, you will have to write down a brief description of the person your witness identified (point to this on the form)...

...There is one more thing I need to explain - The suspect we have placed in the library may or may not be the person your witness interacted with previously. That is his/her decision to make. However, IF your witness identifies this suspect, meaning he/she says that our suspect is the person he/she interacted with previously, YOU will get a $\$ 10$ gift card to Target. However, there are a few rules: First, you may talk to the witness but neither of you should talk to, or interact with, anyone in the library. Second, you should avoid influencing the witness's decision. For instance, you can't tell the witness he/she has to make an identification. And finally, it is important that you do NOT discuss the gift card with the witness, because he/she will not get one; only you will get one if he/she identifies this suspect. Do you understand these rules?" (wait for response)

"Okay, and after your witness has made a decision, you will need to ask your witness how confident he/she is in his/her decision, out of a percentage from 0-100\% (point to the question on the form). You will record that percentage on the form as well... Now wait here and let me go get the other participant." 


\section{APPENDIX E}

\section{Study 2 Administrator Instructions: Showup Condition}

"Now, I am about to give you some instructions for your next task. Once I finish reading you the instructions, you are going to have to follow all the instructions. So it is very important you pay attention to what I am about to explain and if at any time you do not understand me or need me to repeat something, please let me know. Okay?...

...Earlier, the participant that I told to wait at the escalator was called into the hallway to answer some questions. During that time, he/she had a brief interaction with someone. Imagine that the person he/she interacted with committed a crime, and the participant at the escalator is the witness to that crime. Now YOUR job is to pretend you are the police officer in this situation and you will be administering an identification procedure to your witness...

...Imagine, as a police officer, you have a suspect for this crime. We have placed a suspect in this section of the library (pointing towards section). The suspect we have placed here may or may not be the person the witness interacted with previously. We want to know whether the witness will identify this suspect - (walk the administrator to the actor, stopping an appropriate distance away) - That is our suspect (point to the actor - actor should wave). Your job is to take the witness to the suspect and ask the witness if the suspect is the person he/she interacted with previously. You will be responsible for instructing the witness on this procedure. You will also be responsible for recording the decisions that your witness makes."

Hand participant the clipboard and say:

"Your witness may either make an identification or say, 'not there'. In other words, your witness may say that the suspect is the person she interacted with previously or is not the person she interacted with previously. You'll notice the decision options are 'Made 
identification', and 'Did not make identification' (point to this on the form). Based on what the witness tells you, you will have to circle one of these decisions...

...There is one more thing I need to explain - The suspect we have placed in the library may or may not be the person your witness interacted with previously. That is his/her decision to make. However, IF your witness identifies this suspect, meaning he/she says that our suspect is the person he/she interacted with previously, YOU will get a $\$ 10$ gift card to Target. However, there are a few rules: First, you may talk to the witness but neither of you should talk to, or interact with, anyone in the library. Second, you should avoid influencing the witness's decision. For instance, you can't tell the witness he/she has to make an identification. And finally, it is important that you do NOT discuss the gift card with the witness, because he/she will not get one; only you will get one if he/she identifies this suspect. Do you understand these rules?" (wait for response)

"Okay, and after your witness has made a decision, you will need to ask your witness how confident he/she is in his/her decision, out of a percentage from 0-100\% (point to the question on the form). You will record that percentage on the form as well...Now wait here and let me go get the other participant." 


\section{APPENDIX F}

Study 2 Witness Instructions (All conditions)

"Okay, so what we have discussed is that earlier, you were pulled out of the room for a minute and during that time, you interacted with someone just briefly - Do you remember the person who stepped out of the room in the hallway and asked if you were here for a study? She told you about the Developmental Memory study that is up on sona... You should imagine that that person committed a crime and it is now YOUR job to determine whether that person you interacted with previously is here in the library...

...This (indicating the administrator participant) is another participant. You should imagine that he/she is a police officer and he/she is going to administer an identification procedure to you, the witness. The person you interacted with previously may or may not be here - it is YOUR job to either make an identification or say that the person is 'not there'. While you are participating in this procedure, I will be standing back here and I will not be able to hear your conversations or decision so that is why he/she (indicating the administrator participant), as the police officer, will be in charge of recording your decisions... Do you have any questions?" (wait for a response)

"And one more thing - if you make the CORRECT decision, you will both get the shorter version of the follow-up questionnaire, instead of the longer version, after this task. Okay?" (wait for response)

"Okay, the administrator is now going to instruct you on the procedure. But please come back and see me when you are finished." 


\section{APPENDIX G}

Study 2 Administrator Follow-up Questionnaire

ADMINISTRATOR

Questionnaire
Participant \# Date/Time

\section{Demographic Questionnaire}

1. Age

2. Gender

Male Female Prefer not to answer

3. Ethnicity

Caucasian African American Hispanic Asian Other:

4. What is the highest level of education you have completed?

High school diploma

Freshman year of college

Sophomore year of college

Junior year of college

Bachelor's degree

Graduate degree 


\section{Administrator Follow-up Questionnaire}

Please answer the following questions by using the given scale. Please read the questions carefully. Circle your answer:

1. The instructions that I provided to the witness were complete and unbiased.

\begin{tabular}{|c|c|c|c|c|c|c|}
\hline $\begin{array}{l}\text { Strongly } \\
\text { Disagree }\end{array}$ & Disagree & $\begin{array}{c}\text { Somewhat } \\
\text { Disagree }\end{array}$ & $\begin{array}{l}\text { Neither } \\
\text { Disagree }\end{array}$ & $\begin{array}{c}\text { Somewhat } \\
\text { Agree }\end{array}$ & Agree & $\begin{array}{c}\text { Strongly } \\
\text { Agree }\end{array}$ \\
\hline
\end{tabular}

2. I encouraged the witness to identify someone.

\begin{tabular}{|c|c|c|c|c|c|c|}
\hline $\begin{array}{l}\text { Strongly } \\
\text { Disagree }\end{array}$ & Disagree & $\begin{array}{c}\text { Somewhat } \\
\text { Disagree }\end{array}$ & $\begin{array}{l}\text { Neither } \\
\text { Disagree }\end{array}$ & $\begin{array}{c}\text { Somewhat } \\
\text { Agree }\end{array}$ & Agree & $\begin{array}{c}\text { Strongly } \\
\text { Agree }\end{array}$ \\
\hline
\end{tabular}

3. I tried my very best to be fair and impartial throughout the administration of the procedure.

\begin{tabular}{|c|c|c|c|c|c|c|}
\hline $\begin{array}{l}\text { Strongly } \\
\text { Disagree }\end{array}$ & Disagree & $\begin{array}{c}\text { Somewhat } \\
\text { Disagree }\end{array}$ & $\begin{array}{l}\text { Neither } \\
\text { Disagree }\end{array}$ & $\begin{array}{c}\text { Somewhat } \\
\text { Agree }\end{array}$ & Agree & $\begin{array}{c}\text { Strongly } \\
\text { Agree }\end{array}$ \\
\hline
\end{tabular}

4. I encouraged the witness to identify a specific person.

\begin{tabular}{|c|c|c|c|c|c|c|}
\hline $\begin{array}{l}\text { Strongly } \\
\text { Disagree }\end{array}$ & Disagree & $\begin{array}{c}\text { Somewhat } \\
\text { Disagree }\end{array}$ & $\begin{array}{l}\text { Neither } \\
\text { Disagree }\end{array}$ & $\begin{array}{c}\text { Somewhat } \\
\text { Agree }\end{array}$ & Agree & $\begin{array}{c}\text { Strongly } \\
\text { Agree }\end{array}$ \\
\hline
\end{tabular}

5. The witness made a decision without any influence from me.

\begin{tabular}{|c|c|c|c|c|c|c|}
\hline $\begin{array}{l}\text { Strongly } \\
\text { Disagree }\end{array}$ & Disagree & $\begin{array}{c}\text { Somewhat } \\
\text { Disagree }\end{array}$ & $\begin{array}{l}\text { Neither } \\
\text { Disagree }\end{array}$ & $\begin{array}{c}\text { Somewhat } \\
\text { Agree }\end{array}$ & Agree & $\begin{array}{c}\text { Strongly } \\
\text { Agree }\end{array}$ \\
\hline
\end{tabular}


1. Did the research assistant show you who the suspect was in the library? Yes No

2. Were you more motivated to receive a gift card or to receive a short questionnaire? Gift Card Short Questionnaire

3. What is the likelihood that your witness made the correct decision? (0-100\%) $\%$ 


\section{Follow-up Questions}

1. Did you tell your witness that there was a suspect in the library? Circle one.

YES NO

If yes, explain.

2. What instructions did you give to your witness?

3. Do you think you influenced your witness's decision? For instance, did you do anything to indicate what decision your witness should make? Circle one. YES NO

If yes, explain.

4. After your witness made a decision, did you give him/her any feedback on the decision? In other words, did you make any comments about their decision and the likelihood that it was a correct decision? Circle one. YES NO

If yes, explain. 


\section{Questions Regarding the Procedure}

1. How helpful (in your opinion) was the procedure to the witness in reaching an identification decision?

\begin{tabular}{lcccccc} 
Extremely & \multirow{5}{c}{ Neither } & & \\
Unhelpful & Unhelpful & Somewhat & Unhelpful & Somewhat & Helpful & Extremely \\
& & Unhelpful & nor & Helpful & & \\
& & Helpful & & &
\end{tabular}

2. Compared to witnesses who are only shown photos of people (a traditional lineup procedure), witnesses who use this procedure (in general) are probably

$\begin{array}{ccccccc}\text { Much } & & \text { Slightly } & \text { Neither } & \text { Slightly } & & \text { More } \\ \text { Less } & \text { Less } & \text { Less nor } & \text { Moch } \\ \text { Accurate } & \text { Accurate } & \text { Accurate } & \text { More } & \text { More } & \text { Accurate } & \text { More } \\ & & \text { Accurate } & \text { Accurate } & & & \text { Accurate }\end{array}$

3. What is the likelihood that witnesses (in general) will make correct decisions using this procedure?

$(0-100 \%)$ $\%$

4. Are witnesses (in general) more likely to make a correct decision (i.e., identify the suspect if the suspect is guilty and/or say "not there" if the suspect is innocent) using a procedure where the police officer walks them around a particular location and allows them to see if they recognize someone in that location as the perpetrator $\mathrm{OR}$ a procedure where they are shown only the suspect? Circle one:

More likely to be correct using a procedure where witnesses walk around More likely to be correct if only shown the suspect

Explain your answer to \#4. 


\section{APPENDIX H}

Study 2 Witness Follow-up Questionnaire

WITNESS

Questionnaire

Participant \# Date/Time

\section{Demographic Questionnaire}

1. Age

2. Gender

Male Female Prefer not to answer

3. Ethnicity

Caucasian African American Hispanic Asian

Other:

4. What is the highest level of education you have completed?

High school diploma

Freshman year of college

Sophomore year of college

Junior year of college

Bachelor's degree

Graduate degree 
Please answer the following questions by using the given scale. Please read the questions carefully. Circle your answer:

1. How good of a view did you get of the girl you interacted with in the hallway?

$\begin{array}{ccccccc}1 & 2 & 3 & 4 & 5 & 6 & 7 \\ \text { Very poor } & & & & & & \text { Very good }\end{array}$

2. How long would you estimate you viewed the girl's face (in the hallway)?

$\begin{array}{ccccccc}1 & 2 & 3 & 4 & 5 & 6 & 7 \\ \text { Very little time } & & & & & & \text { Quite a bit of time }\end{array}$

3. How well were you able to make out specific features of the girl's face (in the hallway)?

$\begin{array}{ccccccc}1 & 2 & 3 & 4 & 5 & 6 & 7 \\ \text { Not at all } & & & & & & \text { Verywell }\end{array}$

4. How far away was the girl (in the hallway)?

$\begin{array}{lcccccccc}1 & 2 & 3 & 4 & 5 & 6 & 7 & \\ & \text { Notfar } & & & & & & \text { Very far }\end{array}$

5. How much attention were you paying to the girl's face (in the hallway)?

$\begin{array}{ccccccccc}2 & 3 & 4 & 5 & 6 & 7 & \\ & \text { None } & & & & & & \text { My total attention }\end{array}$

6. To what extent do you feel that you had a good basis (enough information) to make an identification decision in the library?

$\begin{array}{lrrrrrr}1 & 2 & 3 & 4 & 5 & 6 & 7 \\ \text { No basis at all } & & & & & \text { A very good basis }\end{array}$


7. How easy or difficult was it for you to figure out whether someone in the library was the girl you interacted with in the hallway?

$\begin{array}{ccccccc}1 & 2 & 3 & 4 & 5 & 6 & 7 \\ \text { Extremely easy } & & & & \text { Extremely difficult }\end{array}$

8. How long do you estimate it took you to make a decision in the library?

$\begin{array}{ccccccc}1 & 2 & 3 & 4 & 5 & 6 & 7 \\ \text { Ineeded almost no time } & & & & & \text { Ineeded a very long time }\end{array}$

9. On the basis of your memory of the girl you interacted with in the hallway, how willing would you be to testify in court that the person you identified/did not identify was/wasn't the person you interacted with in the hallway?

$\begin{array}{ccccccc}1 & 2 & 3 & 4 & 5 & 6 & 7 \\ \text { Not at all willing } & & & & \text { Completely Willing }\end{array}$

10. Generally, how good is your recognition memory for the faces of strangers you have encountered on only one prior occasion.

$\begin{array}{lclllllll}1 & 2 & 3 & 4 & 5 & 6 & 7 & \\ & \text { Very poor }\end{array}$

11. How clear is the image you have in your memory of the person you interacted with in the hallway?

$\begin{array}{ccccccc}1 & 2 & 3 & 4 & 5 & 6 & 7 \\ \text { Not at all clear } & & & & & & \text { Very clear }\end{array}$




\section{Witness Follow-up Questionnaire}

***When the following questions refer to the "administrator", it is asking about the other participant in the library who administered the procedure to you (i.e., the police officer participant).

Please answer the following questions by using the given scale. Please read the questions carefully. Circle your answer:

1. The instructions provided to me by the administrator were complete and unbiased.

\begin{tabular}{|c|c|c|c|c|c|c|}
\hline $\begin{array}{l}\text { Strongly } \\
\text { Disagree }\end{array}$ & Disagree & $\begin{array}{c}\text { Somewhat } \\
\text { Disagree }\end{array}$ & $\begin{array}{l}\text { Neither } \\
\text { Disagree }\end{array}$ & $\begin{array}{c}\text { Somewhat } \\
\text { Agree }\end{array}$ & Agree & $\begin{array}{c}\text { Strongly } \\
\text { Agree }\end{array}$ \\
\hline
\end{tabular}

2. The administrator encouraged me to identify someone in the library.

\begin{tabular}{|c|c|c|c|c|c|c|}
\hline $\begin{array}{l}\text { Strongly } \\
\text { Disagree }\end{array}$ & Disagree & $\begin{array}{c}\text { Somewhat } \\
\text { Disagree }\end{array}$ & $\begin{array}{l}\text { Neither } \\
\text { Disagree }\end{array}$ & $\begin{array}{c}\text { Somewhat } \\
\text { Agree }\end{array}$ & Agree & $\begin{array}{c}\text { Strongly } \\
\text { Agree }\end{array}$ \\
\hline
\end{tabular}

3. The administrator encouraged me to identify a specific person in the library.

\begin{tabular}{|c|c|c|c|c|c|c|}
\hline $\begin{array}{l}\text { Strongly } \\
\text { Disagree }\end{array}$ & Disagree & $\begin{array}{c}\text { Somewhat } \\
\text { Disagree }\end{array}$ & $\begin{array}{l}\text { Neither } \\
\text { Disagree }\end{array}$ & $\begin{array}{c}\text { Somewhat } \\
\text { Agree }\end{array}$ & Agree & $\begin{array}{c}\text { Strongly } \\
\text { Agree }\end{array}$ \\
\hline
\end{tabular}

4. The instructions given to me by the administrator were biased in favor of me choosing someone in particular.

\begin{tabular}{|c|c|c|c|c|c|c|}
\hline $\begin{array}{l}\text { Strongly } \\
\text { Disagree }\end{array}$ & Disagree & $\begin{array}{c}\text { Somewhat } \\
\text { Disagree }\end{array}$ & $\begin{array}{l}\text { Neither } \\
\text { Disagree }\end{array}$ & $\begin{array}{c}\text { Somewhat } \\
\text { Agree }\end{array}$ & Agree & $\begin{array}{c}\text { Strongly } \\
\text { Agree }\end{array}$ \\
\hline
\end{tabular}

5. The administrator appeared to be doing his/her best to be fair and impartial throughout the administration of the procedure.

\begin{tabular}{|c|c|c|c|c|c|c|}
\hline $\begin{array}{l}\text { Strongly } \\
\text { Disagree }\end{array}$ & Disagree & $\begin{array}{c}\text { Somewhat } \\
\text { Disagree }\end{array}$ & $\begin{array}{l}\text { Neither } \\
\text { Disagree }\end{array}$ & $\begin{array}{c}\text { Somewhat } \\
\text { Agree }\end{array}$ & Agree & $\begin{array}{c}\text { Strongly } \\
\text { Agree }\end{array}$ \\
\hline
\end{tabular}


6. The administrator wanted me to pick a certain person in the library.

\begin{tabular}{|c|c|c|c|c|c|c|}
\hline $\begin{array}{l}\text { Strongly } \\
\text { Disagree }\end{array}$ & Disagree & $\begin{array}{c}\text { Somewhat } \\
\text { Disagree }\end{array}$ & $\begin{array}{l}\text { Neither } \\
\text { Disagree }\end{array}$ & $\begin{array}{c}\text { Somewhat } \\
\text { Agree }\end{array}$ & Agree & $\begin{array}{c}\text { Strongly } \\
\text { Agree }\end{array}$ \\
\hline
\end{tabular}

7. I made my decision without any input from the administrator.

\begin{tabular}{|c|c|c|c|c|c|c|}
\hline $\begin{array}{l}\text { Strongly } \\
\text { Disagree }\end{array}$ & Disagree & $\begin{array}{c}\text { Somewhat } \\
\text { Disagree }\end{array}$ & $\begin{array}{l}\text { Neither } \\
\text { Disagree }\end{array}$ & $\begin{array}{c}\text { Somewhat } \\
\text { Agree }\end{array}$ & Agree & $\begin{array}{c}\text { Strongly } \\
\text { Agree }\end{array}$ \\
\hline
\end{tabular}

8. I believe the administrator's behavior probably influenced my decision.

\begin{tabular}{|c|c|c|c|c|c|c|}
\hline $\begin{array}{l}\text { Strongly } \\
\text { Disagree }\end{array}$ & Disagree & $\begin{array}{c}\text { Somewhat } \\
\text { Disagree }\end{array}$ & $\begin{array}{l}\text { Neither } \\
\text { Disagree }\end{array}$ & $\begin{array}{c}\text { Somewhat } \\
\text { Agree }\end{array}$ & Agree & $\begin{array}{c}\text { Strongly } \\
\text { Agree }\end{array}$ \\
\hline
\end{tabular}




\section{Follow-up Questions}

1. Did the administrator tell you that a suspect was placed somewhere in the library? Circle one.

YES NO

2. What instructions did the administrator give you?

3. Do you think the administrator influenced your decision? For instance, did the administrator do anything to indicate what decision you should make? Circle one.

YES NO

If yes, explain.

4. How did you make your decision in the library?

5. After you made a decision, did your administrator give you any feedback on the decision? In other words, did he/she make any comments about your decision and the likelihood that it was a correct decision? Circle one. YES NO

If yes, explain.

6. Do you know or have you ever seen the girl you interacted with in the hallway (before you participated in this study)? Circle one. YES NO 


\section{Questions Regarding the Procedure}

1. How helpful was the procedure in which you participated in reaching an identification decision?

\begin{tabular}{lcccccc} 
Extremely & \multirow{5}{c}{ Neither } & & & \\
Unhelpful & Unhelpful & Somewhat & Unhelpful & Somewhat & Helpful & Extremely \\
& & Unhelpful & nor & Helpful & & \\
& & Helpful & & &
\end{tabular}

2. Compared to witnesses who are only shown photos of people (a traditional lineup procedure), witnesses who use this procedure (in general) are probably

$\begin{array}{ccccccc}\text { Much } & & \text { Slightly } & \text { Neither } & \text { Slightly } & \text { More } & \text { Much } \\ \text { Less } & \text { Less } & \text { Less } & \text { Less nor } & \text { More } & \text { Accurate } & \text { More } \\ \text { Accurate } & \text { Accurate } & \text { Accurate } & \text { More } & \text { Accurate } & \text { Accurate } & \text { Accurate }\end{array}$

3. What is the likelihood that witnesses (in general) will make correct decisions using this procedure? $(0-100 \%)$ $\%$

4. Are witnesses (in general) more likely to make a correct decision (i.e., identify the suspect if the suspect is guilty and/or say "not there" if the suspect is innocent) using a procedure where the police officer walks them around a particular location and allows them to see if they recognize someone in that location as the perpetrator OR a procedure where they are shown only the suspect? Circle one:

More likely to be correct using a procedure where witnesses walk around More likely to be correct if only shown the suspect

Explain your answer to \#4. 
Table 1

Study 1 Target/Filler Similarity Ratings

\begin{tabular}{|c|c|c|c|c|c|c|c|c|c|c|c|c|}
\hline & $\mathrm{T} 1$ & $\mathrm{~T} 2$ & Sim 1 & $\operatorname{Sim} 2$ & Sim3 & Sim 4 & Sim5 & Dis1 & Dis2 & Dis3 & Dis4 & Dis5 \\
\hline $\mathrm{T} 1$ & ---- & & & & & & & & & & & \\
\hline $\mathrm{T} 2$ & 6.00 & ---- & & & & & & & & & & \\
\hline Sim1 & 5.33 & 3.67 & ---- & & & & & & & & & \\
\hline $\operatorname{Sim} 2$ & 4.33 & 2.00 & 2.33 & ---- & & & & & & & & \\
\hline $\operatorname{Sim} 3$ & 5.67 & 3.00 & 4.33 & 4.67 & ---- & & & & & & & \\
\hline $\operatorname{Sim} 4$ & 4.67 & 5.33 & 3.33 & 4.33 & 5.33 & ---- & & & & & & \\
\hline Sim5 & 2.67 & 4.67 & 3.00 & 2.67 & 2.33 & 3.67 & ---- & & & & & \\
\hline Dis1 & 3.00 & 1.67 & 3.67 & 3.33 & 5.33 & 3.33 & 2.33 & ---- & & & & \\
\hline Dis2 & 3.33 & 2.33 & 4.33 & 4.00 & 4.00 & 2.67 & 3.67 & 3.33 & ---- & & & \\
\hline Dis3 & 1.00 & 3.00 & 4.00 & 3.00 & 4.33 & 4.67 & 2.33 & 4.00 & 3.67 & ---- & & \\
\hline Dis4 & 2.00 & 2.33 & 1.67 & 2.33 & 1.67 & 3.00 & 1.33 & 1.67 & 1.33 & 2.67 & ---- & \\
\hline Dis5 & 3.00 & 2.67 & 3.67 & 4.00 & 3.67 & 3.33 & 3.33 & 4.67 & 3.67 & 4.67 & 3.00 & ---- \\
\hline
\end{tabular}

Note $: \mathrm{T}=$ target Sim = similar filler; Dis = dissimilar filler. Targets and fillers are numbered in no particular order. 
Table 2

Study 1 Proportion of Choosing and Suspect Identifications for Overall Procedure Comparisons

\begin{tabular}{|c|c|c|c|}
\hline & Field View & Lineup & Showup \\
\hline & \multicolumn{3}{|c|}{ Choosing } \\
\hline $\begin{array}{l}\text { Target } \\
\text { Present }\end{array}$ & $\begin{array}{c}.72 \\
n=54\end{array}$ & $\begin{array}{c}.69 \\
n=52\end{array}$ & $\begin{array}{c}.66 \\
n=25\end{array}$ \\
\hline $\begin{array}{l}\text { Target } \\
\text { Absent }\end{array}$ & $\begin{array}{c}.36 \\
n=28\end{array}$ & $\begin{array}{c}.36 \\
n=28\end{array}$ & $\begin{array}{c}.05 \\
n=2\end{array}$ \\
\hline & \multicolumn{3}{|c|}{ Suspect Identifications } \\
\hline $\begin{array}{c}\text { Target } \\
\text { Present } \\
\text { (Correct ID) }\end{array}$ & $\begin{array}{c}.64 \\
n=48\end{array}$ & $\begin{array}{c}.56 \\
n=42\end{array}$ & $\begin{array}{c}.66 \\
n=25\end{array}$ \\
\hline $\begin{array}{c}\text { Target } \\
\text { Absent } \\
\text { (False ID) }\end{array}$ & $\begin{array}{c}.36 \\
n=28\end{array}$ & $\begin{array}{c}.13 \\
n=10\end{array}$ & $\begin{array}{c}.05 \\
n=2\end{array}$ \\
\hline
\end{tabular}


Table 3

Logistic Regressions Predicting Choosing and Suspect Identification Rates: Field View vs. Lineup

\begin{tabular}{|c|c|c|c|c|c|c|c|c|}
\hline & & & & & & Odds & $\begin{array}{l}95 \% \\
\text { Odd }\end{array}$ & $\begin{array}{l}\text { I.for } \\
\text { Ratio }\end{array}$ \\
\hline & $\mathrm{B}$ & S.E. & Wald & df & $p$ & Ratio & Lower & Upper \\
\hline & \multicolumn{8}{|c|}{$\mathrm{DV}=$ Choosing } \\
\hline Procedure & .00 & .33 & .00 & 1 & 1.00 & 1.00 & .52 & 1.92 \\
\hline $\begin{array}{l}\text { Target } \\
\text { Presence }\end{array}$ & 1.52 & .35 & 19.07 & 1 & .000 & 19.105 & 2.32 & 9.10 \\
\hline \multirow[t]{2}{*}{ Interaction } & -.13 & .49 & .07 & 1 & .793 & .327 & .34 & 2.30 \\
\hline & \multicolumn{8}{|c|}{ DV $=$ Suspect Identifications } \\
\hline Procedure & -1.34 & .41 & 10.49 & 1 & .001 & .26 & .12 & .59 \\
\hline $\begin{array}{l}\text { Target } \\
\text { Presence }\end{array}$ & 1.16 & .34 & 11.75 & 1 & .001 & 3.18 & 1.64 & 6.15 \\
\hline Interaction & 1.00 & .51 & 3.56 & 1 & .059 & 2.73 & .96 & 7.73 \\
\hline
\end{tabular}


Table 4

Logistic Regressions Predicting Choosing and Suspect Identification Rates: Field View vs. Showup

\begin{tabular}{|c|c|c|c|c|c|c|c|c|}
\hline & \multirow[b]{2}{*}{$\mathrm{B}$} & \multirow[b]{2}{*}{ S.E. } & \multirow[b]{2}{*}{ Wald } & \multirow[b]{2}{*}{ df } & \multirow[b]{2}{*}{$p$} & \multirow{2}{*}{$\begin{array}{l}\text { Odds } \\
\text { Ratio } \\
\end{array}$} & \multicolumn{2}{|c|}{$\begin{array}{l}\text { 95\% C.I.for } \\
\text { Odds Ratio }\end{array}$} \\
\hline & & & & & & & Lower & Upper \\
\hline & \multicolumn{8}{|c|}{ DV $=$ Choosing } \\
\hline Procedure & -2.34 & .76 & 9.38 & 1 & .002 & .10 & .02 & .43 \\
\hline Target & 1.52 & .35 & 19.07 & 1 & .000 & 4.59 & 2.32 & 9.10 \\
\hline \multirow[t]{2}{*}{ Interaction } & 2.05 & .88 & 5.47 & 1 & .019 & 7.75 & 1.39 & 43.06 \\
\hline & \multicolumn{8}{|c|}{ DV $=$ Suspect Identifications } \\
\hline Procedure & -2.34 & .76 & 9.38 & 1 & .002 & .10 & .02 & .43 \\
\hline Target & 1.16 & .34 & 11.75 & 1 & .001 & 3.18 & 1.64 & 6.15 \\
\hline Presence & & & & & & & & \\
\hline Interaction & 2.42 & .87 & 7.71 & 1 & .005 & 11.21 & 2.04 & 61.71 \\
\hline
\end{tabular}


Table 5

Logistic Regressions Predicting Choosing and Suspect Identification Rates: Lineup vs. Showup

\begin{tabular}{|c|c|c|c|c|c|c|c|c|}
\hline & & & & & & Odds & $\begin{array}{l}95 \% \\
\text { Odds }\end{array}$ & $\begin{array}{l}\text { I.for } \\
\text { Ratio }\end{array}$ \\
\hline & $\mathrm{B}$ & S.E. & Wald & df & $p$ & Ratio & Lower & Upper \\
\hline & \multicolumn{8}{|c|}{$\mathrm{DV}=$ Choosing } \\
\hline Procedure & 2.34 & .76 & 9.38 & 1 & .002 & 10.36 & 2.32 & 46.25 \\
\hline $\begin{array}{l}\text { Target } \\
\text { Presence }\end{array}$ & 3.57 & .80 & 19.81 & 1 & .000 & 35.58 & 7.38 & 171.49 \\
\hline \multirow[t]{2}{*}{ Interaction } & -2.18 & .87 & 6.21 & 1 & .013 & .11 & .02 & .63 \\
\hline & \multicolumn{8}{|c|}{ DV $=$ Suspect Identifications } \\
\hline Procedure & 1.00 & .80 & 1.56 & 1 & .212 & 2.72 & .57 & 13.08 \\
\hline $\begin{array}{l}\text { Target } \\
\text { Presence }\end{array}$ & 3.57 & .80 & 19.81 & 1 & .000 & 35.58 & 7.38 & 171.49 \\
\hline Interaction & -1.41 & .90 & 2.46 & 1 & .117 & .24 & .04 & 1.42 \\
\hline
\end{tabular}


Table 6

Study 1 Proportion of Choosing and Suspect Identifications as a Function of Filler Similarity

\begin{tabular}{|c|c|c|c|c|c|}
\hline & \multicolumn{2}{|c|}{ Field View } & \multicolumn{2}{|c|}{ Lineup } & \multirow[t]{2}{*}{ Showup } \\
\hline & Similar & Dissimilar & Similar & Dissimilar & \\
\hline & \multicolumn{5}{|c|}{ Choosing } \\
\hline $\begin{array}{c}\text { Target } \\
\text { Present }\end{array}$ & $\begin{array}{c}.76 \\
n=26\end{array}$ & $\begin{array}{c}.68 \\
n=28\end{array}$ & $\begin{array}{c}.68 \\
n=28\end{array}$ & $\begin{array}{c}.71 \\
n=24\end{array}$ & $\begin{array}{c}.66 \\
n=25\end{array}$ \\
\hline $\begin{array}{c}\text { Target } \\
\text { Absent }\end{array}$ & $\begin{array}{c}.34 \\
n=14\end{array}$ & $\begin{array}{c}.38 \\
n=14\end{array}$ & $\begin{array}{c}.40 \\
n=14\end{array}$ & $\begin{array}{c}.33 \\
n=14\end{array}$ & $\begin{array}{c}.05 \\
n=2\end{array}$ \\
\hline & \multicolumn{5}{|c|}{ Suspect Identifications } \\
\hline $\begin{array}{c}\text { Target } \\
\text { Present } \\
\text { (Correct ID) }\end{array}$ & $\begin{array}{c}.65 \\
n=22\end{array}$ & $\begin{array}{c}.63 \\
n=26\end{array}$ & $\begin{array}{c}.54 \\
n=22\end{array}$ & $\begin{array}{c}.59 \\
n=20\end{array}$ & $\begin{array}{c}.66 \\
n=25\end{array}$ \\
\hline $\begin{array}{c}\text { Target } \\
\text { Absent } \\
\text { (False ID) }\end{array}$ & $\begin{array}{c}.34 \\
n=14\end{array}$ & $\begin{array}{c}.38 \\
n=14\end{array}$ & $\begin{array}{c}.06 \\
n=2\end{array}$ & $\begin{array}{c}.19 \\
n=8\end{array}$ & $\begin{array}{c}.05 \\
n=2\end{array}$ \\
\hline
\end{tabular}


Table 7

Logistic Regressions Predicting Choosing and Suspect Identification Rates: Lineups (Similar vs. Dissimilar)

\begin{tabular}{|c|c|c|c|c|c|c|c|c|}
\hline & \multirow[b]{2}{*}{$\mathrm{B}$} & \multirow[b]{2}{*}{ S.E. } & \multirow[b]{2}{*}{ Wald } & \multirow[b]{2}{*}{$\mathrm{df}$} & \multirow[b]{2}{*}{$p$} & \multirow{2}{*}{$\begin{array}{l}\text { Odds } \\
\text { Ratio }\end{array}$} & \multicolumn{2}{|c|}{$\begin{array}{l}\text { 95\% C.I.for } \\
\text { Odds Ratio }\end{array}$} \\
\hline & & & & & & & Lower & Upper \\
\hline & \multicolumn{8}{|c|}{$\mathrm{DV}=$ Choosing } \\
\hline Filler & -.32 & .47 & .46 & 1 & .496 & .72 & .29 & 1.84 \\
\hline Similarity & & & & & & & & \\
\hline $\begin{array}{l}\text { Target } \\
\text { Presence }\end{array}$ & 1.17 & .48 & 5.94 & 1 & .015 & 3.23 & 1.26 & 8.30 \\
\hline \multirow[t]{2}{*}{ Interaction } & .43 & .69 & .39 & 1 & .534 & 1.54 & .40 & 5.98 \\
\hline & \multicolumn{8}{|c|}{ DV $=$ Suspect Identifications } \\
\hline Filler & 1.33 & .83 & 2.58 & 1 & .108 & 3.77 & .75 & 19.07 \\
\hline Similarity & & & & & & & & \\
\hline $\begin{array}{l}\text { Target } \\
\text { Presence }\end{array}$ & 2.95 & .79 & 13.85 & 1 & .000 & 19.11 & 4.04 & 90.35 \\
\hline Interaction & -1.12 & .95 & 1.38 & 1 & .240 & .33 & .05 & 2.11 \\
\hline
\end{tabular}


Table 8

Logistic Regressions Predicting Choosing and Suspect Identification Rates: Field Views (Similar vs. Dissimilar)

\begin{tabular}{|c|c|c|c|c|c|c|c|c|}
\hline & & & & & & Odds & $\begin{array}{l}95 \% \\
\text { Odd }\end{array}$ & $\begin{array}{l}\text { I.for } \\
\text { Ratio }\end{array}$ \\
\hline & $\mathrm{B}$ & S.E. & Wald & df & $p$ & Ratio & Lower & Upper \\
\hline & \multicolumn{8}{|c|}{$\mathrm{DV}=$ Choosing } \\
\hline Filler & .16 & .47 & .12 & 1 & .734 & 1.17 & .47 & 2.96 \\
\hline Similarity & & & & & & & & \\
\hline $\begin{array}{l}\text { Target } \\
\text { Presence }\end{array}$ & 1.84 & .52 & 12.39 & 1 & .000 & 6.27 & 2.26 & 17.42 \\
\hline \multirow[t]{2}{*}{ Interaction } & -.57 & .71 & .65 & 1 & .419 & .57 & .14 & 2.26 \\
\hline & \multicolumn{8}{|c|}{ DV $=$ Suspect Identifications } \\
\hline Filler & .16 & .47 & .12 & 1 & .734 & 1.17 & .47 & 2.96 \\
\hline Similarity & & & & & & & & \\
\hline $\begin{array}{l}\text { Target } \\
\text { Presence }\end{array}$ & 1.26 & .49 & 6.72 & 1 & .010 & 3.54 & 1.36 & 9.19 \\
\hline Interaction & -.22 & .68 & .10 & 1 & .749 & .81 & .21 & 3.03 \\
\hline
\end{tabular}


Table 9

Study 2 Proportion of Choosing and Suspect Identifications for Overall Field View (Non-blind and Blind), Showup, Non-blind Field View, and Blind Field View

\begin{tabular}{ccccc} 
& $\begin{array}{c}\text { Overall } \\
\text { Field View }\end{array}$ & Showup & $\begin{array}{c}\text { Non-blind } \\
\text { Field View }\end{array}$ & $\begin{array}{c}\text { Blind } \\
\text { Field View }\end{array}$ \\
& \multicolumn{4}{c}{ Choosing } \\
Target & .44 & .45 & .45 & .43 \\
Present & $n=27$ & $n=14$ & $n=14$ & $n=13$ \\
Target & .16 & .20 & .23 & .09 \\
Absent & $n=10$ & $n=6$ & $n=7$ & $n=3$ \\
\hline & & Suspect Identifications & \\
Target & .41 & & & .37 \\
Present & $n=25$ & $n=14$ & $n=14$ & $n=11$ \\
(Correct ID) & & & .45 & .06 \\
Target & .11 & .20 & .16 & $n=2$ \\
Absent & $n=7$ & $n=6$ & $n=5$ & \\
(False ID) & & & & \\
\hline
\end{tabular}


Table 10

Logistic Regressions Predicting Choosing and Suspect Identification Rates: Overall Field View (Blind and Non-blind) vs. Showup

\begin{tabular}{|c|c|c|c|c|c|c|c|c|}
\hline & & & & & & Odds & $\begin{array}{l}95 \% \\
\text { Odds }\end{array}$ & 95\% C.I.for \\
\hline & $\mathrm{B}$ & S.E. & Wald & $\mathrm{df}$ & $p$ & Ratio & Lower & Upper \\
\hline & \multicolumn{8}{|c|}{$\mathrm{DV}=$ Choosing } \\
\hline Procedure & -.28 & .57 & .24 & 1 & .623 & .76 & .25 & 2.32 \\
\hline $\begin{array}{l}\text { Target } \\
\text { Presence }\end{array}$ & -1.44 & .43 & 11.15 & 1 & .001 & .24 & .10 & .55 \\
\hline \multirow[t]{2}{*}{ Interaction } & .25 & .72 & .12 & 1 & .735 & 1.28 & .31 & 5.28 \\
\hline & \multicolumn{8}{|c|}{ DV $=$ Suspect Identifications } \\
\hline Procedure & .69 & .61 & 1.30 & 1 & .254 & 2.00 & .61 & 6.58 \\
\hline $\begin{array}{l}\text { Target } \\
\text { Presence }\end{array}$ & 1.72 & .48 & 12.87 & 1 & .000 & 5.56 & 2.18 & 14.18 \\
\hline Interaction & -.52 & .75 & .48 & 1 & .488 & .59 & .14 & 2.59 \\
\hline
\end{tabular}


Table 11

Logistic Regressions Predicting Choosing and Suspect Identification Rates: Non-blind Field View vs. Blind Field View

\begin{tabular}{|c|c|c|c|c|c|c|c|c|}
\hline & \multirow[b]{2}{*}{$\mathrm{B}$} & \multirow[b]{2}{*}{ S.E. } & \multirow[b]{2}{*}{ Wald } & \multirow[b]{2}{*}{$\mathrm{df}$} & \multirow[b]{2}{*}{$p$} & \multirow{2}{*}{$\begin{array}{l}\text { Odds } \\
\text { Ratio } \\
\end{array}$} & \multicolumn{2}{|c|}{$\begin{array}{l}\text { 95\% C.I.for } \\
\text { Odds Ratio }\end{array}$} \\
\hline & & & & & & & Lower & Upper \\
\hline & \multicolumn{8}{|c|}{$\mathrm{DV}=$ Choosing } \\
\hline Administration & -1.06 & .88 & 1.45 & 1 & .228 & .35 & .06 & 1.94 \\
\hline $\begin{array}{l}\text { Target } \\
\text { Presence }\end{array}$ & 1.46 & .61 & 5.74 & 1 & .017 & 4.28 & 1.30 & 14.08 \\
\hline \multirow[t]{2}{*}{ Interaction } & .71 & 1.02 & .48 & 1 & .489 & 2.03 & .27 & 15.05 \\
\hline & \multicolumn{8}{|c|}{ DV $=$ Suspect Identifications } \\
\hline Administration & 1.04 & .74 & 1.95 & 1 & .163 & 2.82 & .66 & 12.10 \\
\hline $\begin{array}{l}\text { Target } \\
\text { Presence }\end{array}$ & -1.04 & .56 & 3.42 & 1 & .064 & .35 & .12 & 1.06 \\
\hline Interaction & -.96 & .91 & 1.13 & 1 & .287 & .38 & .07 & 2.25 \\
\hline
\end{tabular}


Table 12

Logistic Regressions Predicting Choosing and Suspect Identification Rates: Non-blind Field View vs. Showup

\begin{tabular}{|c|c|c|c|c|c|c|c|c|}
\hline & \multirow[b]{2}{*}{$\mathrm{B}$} & \multirow[b]{2}{*}{ S.E. } & \multirow[b]{2}{*}{ Wald } & \multirow[b]{2}{*}{$\mathrm{df}$} & \multirow[b]{2}{*}{$p$} & \multirow{2}{*}{$\begin{array}{l}\text { Odds } \\
\text { Ratio } \\
\end{array}$} & \multicolumn{2}{|c|}{$\begin{array}{l}95 \% \text { C.I.for } \\
\text { Odds Ratio }\end{array}$} \\
\hline & & & & & & & Lower & Upper \\
\hline & \multicolumn{8}{|c|}{$\mathrm{DV}=$ Choosing } \\
\hline Procedure & .15 & .63 & .06 & 1 & .806 & 1.17 & .34 & 3.99 \\
\hline $\begin{array}{l}\text { Target } \\
\text { Presence }\end{array}$ & -1.04 & .56 & 3.42 & 1 & .064 & .35 & .12 & 1.06 \\
\hline \multirow[t]{2}{*}{ Interaction } & -.15 & .81 & .04 & 1 & .849 & .86 & .18 & 4.18 \\
\hline & \multicolumn{8}{|c|}{ DV $=$ Suspect Identifications } \\
\hline Procedure & .26 & .67 & .15 & 1 & .695 & 1.30 & .35 & 4.82 \\
\hline $\begin{array}{l}\text { Target } \\
\text { Presence }\end{array}$ & 1.46 & .61 & 5.74 & 1 & .017 & 4.28 & 1.30 & 14.08 \\
\hline Interaction & -.26 & .84 & .10 & 1 & .755 & .77 & .15 & 4.00 \\
\hline
\end{tabular}


Table 13

Logistic Regressions Predicting Choosing and Suspect Identification Rates: Blind Field View vs. Showup

\begin{tabular}{|c|c|c|c|c|c|c|c|c|}
\hline & & & & & & Odds & \multicolumn{2}{|c|}{$\begin{array}{l}\text { 95\% C.I.for } \\
\text { Odds Ratio }\end{array}$} \\
\hline & $\mathrm{B}$ & S.E. & Wald & $\mathrm{df}$ & $p$ & Ratio & Lower & Upper \\
\hline & \multicolumn{8}{|c|}{$\mathrm{DV}=$ Choosing } \\
\hline Procedure & -.88 & .76 & 1.35 & 1 & .245 & .41 & .09 & 1.83 \\
\hline $\begin{array}{l}\text { Target } \\
\text { Presence }\end{array}$ & -2.00 & .71 & 7.95 & 1 & .005 & .14 & .03 & .54 \\
\hline \multirow[t]{2}{*}{ Interaction } & .81 & .92 & .78 & 1 & .378 & 2.24 & .37 & 13.56 \\
\hline & \multicolumn{8}{|c|}{ DV $=$ Suspect Identifications } \\
\hline Procedure & 1.32 & .86 & 2.36 & 1 & .125 & 3.75 & .69 & 20.28 \\
\hline $\begin{array}{l}\text { Target } \\
\text { Presence }\end{array}$ & 2.16 & .82 & 6.90 & 1 & .009 & 8.68 & 1.73 & 43.56 \\
\hline Interaction & -.97 & 1.01 & .93 & 1 & .336 & .38 & .05 & 2.73 \\
\hline
\end{tabular}




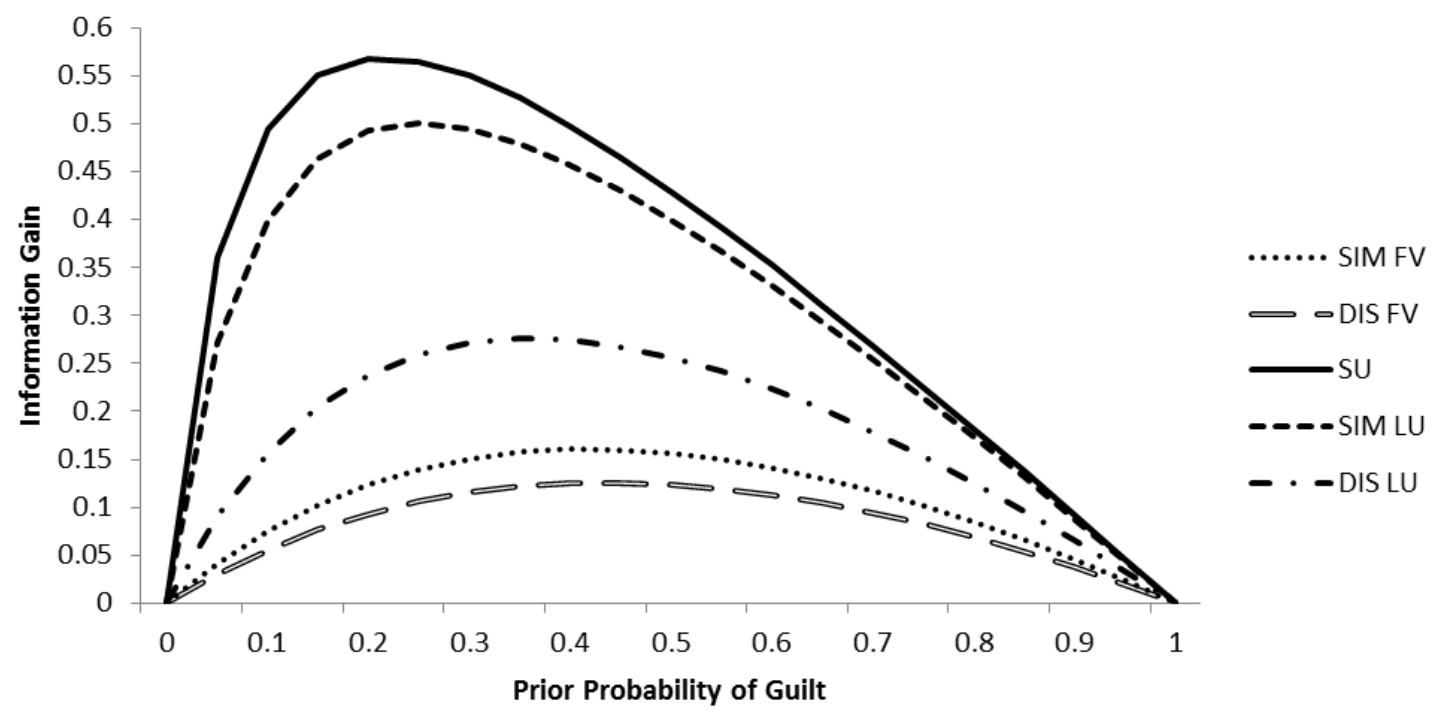

Figure 1. Study 1: Information gain from identification of suspect as a function of procedure.

Note: SIM FV = field view with similar fillers; DIS FV = field view with dissimilar fillers; SU = showup; SIM LU = lineup with similar fillers; DIS LU = lineup with dissimilar fillers 


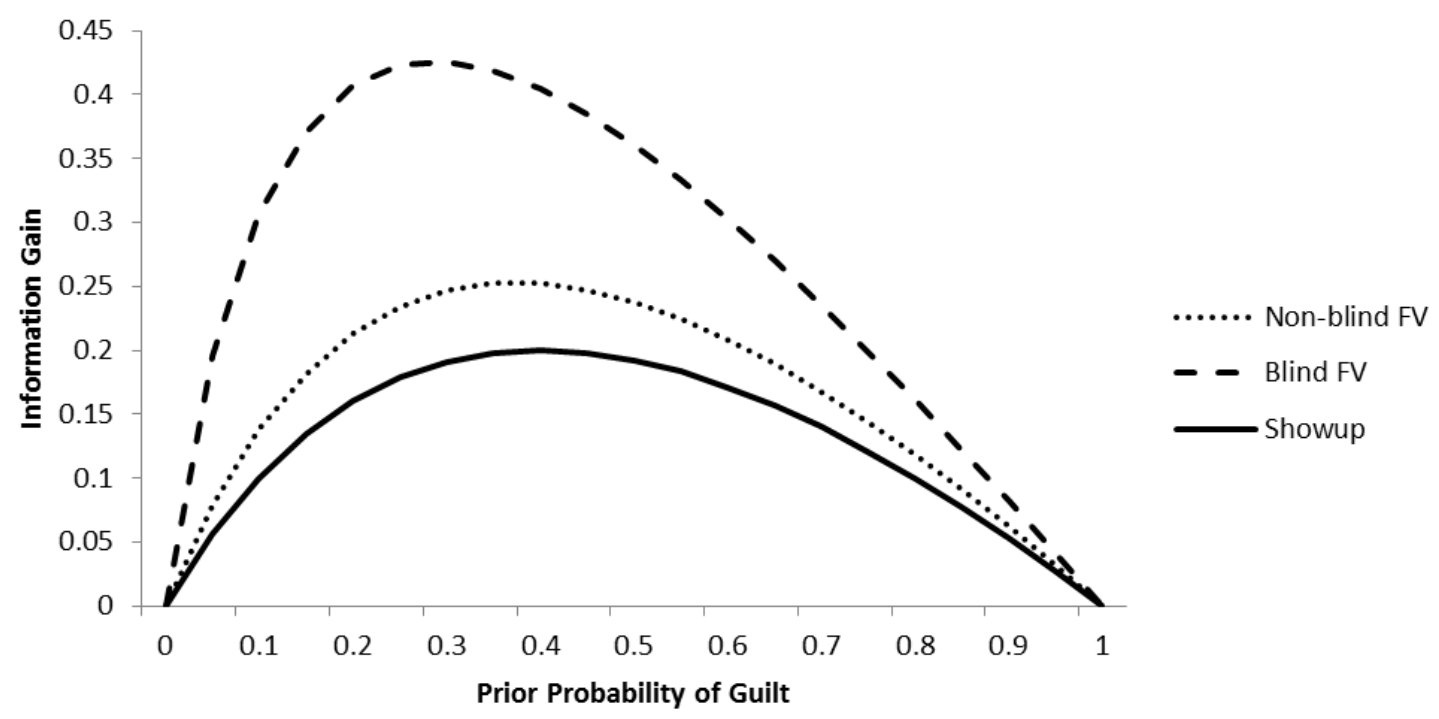

Figure 2. Study 2: Information gain from identification of suspect as a function of procedure. 


\section{MELISSA KAVETSKI}

May 2009

May 2011

August 2016
B.A. Psychology (minor in Sociology)

St. Mary's University

San Antonio, Texas

M.A., General Psychology

Stephen F. Austin State University

Nacogdoches, Texas

Ph.D., Legal Psychology

Florida International University

Miami, Florida

\section{PUBLICATIONS AND PRESENTATIONS}

Kavetski, M. \& Charman, S. (2016, March). An examination of law enforcement decision-making during criminal investigations. Paper presented at the $5^{\text {th }}$ Annual Forensic Symposium, Miami, Florida. Presented by Kavetski, M.

Kavetski, M., \& Charman, S. (2016, March). The suggestiveness of showups: An effect of administration or base rate beliefs of guilt? Paper presented at the American Psychology-Law Society (AP-LS) Annual Conference, Atlanta, Georgia. Presented by Kavetski, M.

Kavetski, M. \& Evans, J. (2016, March). The use of witness calibration as a tool to evaluate witness credibility. Poster presented at the American Psychology-Law Society (AP-LS) Annual Conference, Atlanta, Georgia.

Kavetski, M. \& Evans, J. (2015, June). Does evidence that witnesses are using metacognitive monitoring and control affect mock jurors' evaluations of witness credibility? Poster presented at Society for Applied Research in Memory and Cognition (SARMAC) XI, Victoria, B. C., Canada.

Kavetski, M., Charman, S., \& Hirn Mueller, D. (2015, March). Biased decision-making among police officers: Do beliefs of guilt predict the evaluation of ambiguous evidence? Paper presented at the American Psychology-Law Society (AP-LS) Annual Conference, San Diego, California. Presented by Kavetski, M.

Charman, S., Hirn Mueller, D., \& Kavetski, M. (2014, March). Law enforcement decision-making. Paper presented at the American Psychology-Law Society (APLS) Annual Conference, New Orleans, Louisiana. Presented by Kavetski, M. 
Kavetski, M. \& Topp, L. (2012, March). An examination of the elimination lineup on decision making strategies and the own-race bias. Poster presented at the American Psychology-Law Society (AP-LS) Annual Conference, San Juan, Puerto Rico.

Terranova, A. M., Harris, J., Kavetski, M., \& Oates, R. (2011). Responding to Peer Victimization in Late Childhood: A Sense of Control Matters. Child Youth Care Forum, 40, 419-434.

Kavetski, M., Terranova, A. M., \& Petty, K. (2011, April). Narrowing the victim pool: Do bullies narrow down their group of targets? Poster presented at the Annual Meeting of the Southwestern Psychological Association (SWPA) Conference, San Antonio, TX.

Johnson, S., Kavetski, M., \& Johnson, J. (2011, April). The effects of confirmation bias instructions and strength of evidence on convictions. Poster presented at the Annual Meeting of the Southwestern Psychological Association (SWPA) Conference, San Antonio, TX.

Kavetski, M., Buuck, N., Tatum, E. \& Terranova, A. M. (2010, April). Social information processing model and aggression in college students. Poster presented at the Annual Meeting of the Southwestern Psychological Association (SWPA) Conference, Dallas, TX.

Kavetski, M. \& Topp, L. (2010, March). The influence of processing orientation training on the effects of the own-race bias. Poster presented at the American PsychologyLaw Society (AP-LS) Annual Conference, Vancouver, Canada.

Kavetski, M., Adame, C. \& Frederick, D. (2007, March). Discrimination and prejudice attitudes as a result of self-esteem issues. Poster presented at the Regional Psychology Research Conference, Our Lady of the Lake University, San Antonio, TX.

Adame, C., Frederick, D., \& Kavetski, M. (2007, March). The relationship between discrimination, prejudice, and self-esteem. Poster presented at the $8^{\text {th }}$ Annual Undergraduate Research Symposium \& Creative Activities Exhibition, St. Mary's University, San Antonio, TX. 